\title{
Review of Clinically and Epidemiologically Relevant Coagulase-Negative Staphylococci in Africa
}

\author{
Jonathan Asante, ${ }^{1,2}$ Daniel G. Amoako, ${ }^{1}$ Akebe L.K. Abia, ${ }^{1}$ Anou M. Somboro, ${ }^{2,3}$ \\ Usha Govinden, ${ }^{1}$ Linda A. Bester, ${ }^{3}$ and Sabiha Y. Essack ${ }^{1}$
}

Coagulase-negative staphylococci (CoNS) have engendered substantial interest in recent years as pathogenic causes of infections in both human and veterinary medicine, especially in the immunocompromised, critically ill, long-term hospitalized and in those harboring invasive medical devices such as catheters. They have been implicated in infections such as urinary tract infections, bloodstream infections, and invasive device-related infections, and are responsible for substantial economic losses in livestock production. The advancement of diagnostic techniques has increased our understanding of their molecular mechanisms of pathogenicity, even though distinguishing between innocuousness and pathogenicity is still challenging.

The incidence of CoNS varied across the continent in humans and animals (mainly cattle), ranging from $6 \%$ to $68 \%$ in suspected human infections and from $3 \%$ to $61.7 \%$ in suspected animal infections, distributed across different geographic locations. Furthermore, there were varying antibiotic resistance patterns observed in CoNS isolates, with high methicillin resistance in some cases, leading to crossresistance against many antibiotics. Staphylococcus epidermidis, Staphylococcus haemolyticus, and Staphylococcus xylosus were most commonly reported in studies herein reviewed, while the enterotoxin $\mathrm{C}$ gene, atl E gene, ica gene, and hemolysin virulence factors were linked with enhanced pathogenicity. Advancement in identification and typing methods, including whole genome sequencing, virulence screening, and the assessment of the immune status of subjects in studies will help to thoroughly assess the true pathogenic potential of isolated CoNS species in developing countries. Careful antibiotic stewardship guidelines should be followed due to the ability of CoNS to develop multidrug resistance.

Keywords: coagulase-negative staphylococci, Africa, antimicrobial resistance, epidemiology, pathogenicity

\section{Introduction}

C OAgUlASE-NEgATIVE STAPHYLOCOCCI (CoNS) are increasingly becoming a global public health threat due to increased antibiotic resistance and invasive surgical procedures, which increase the risk of exposure. ${ }^{1}$ Even though CoNS are usually considered innocuous, they are frequently associated with nosocomial infections, leading to greater interest in them as relevant pathogens rather than mere contaminants. ${ }^{1,2}$ Bacterial eye infections, ${ }^{3}$ prosthetic joint infections, ${ }^{4}$ urinary tract infections (UTIs) especially among immunocompromised patients, ${ }^{5}$ surgical site infections, ${ }^{6}$ infective endocarditis ${ }^{7}$ and cattle mastitis ${ }^{8}$ are some conditions that have been associated with CoNS. ${ }^{9}$

Because CoNS usually form part of the microbiota of the skin and mucous membranes, proper differentiation between clinically significant and contaminant bacteria is important in bacterial etiology of suspected infections. Staphylococcus epidermidis is the most frequently encountered CoNS species in laboratories; notwithstanding other clinically relevant CoNS species, such as Staphylococcus saprophyticus, Staphylococcus haemolyticus, Staphylococcus schleifieri, Staphylococcus xylosus, Staphylococcus hominis and Staphylococcus lugdunensis that are known to cause infections in humans. ${ }^{1}$

It is known that the formation of biofilm facilitates the pathogenicity of CoNS by enhancing their ability to adhere to surfaces of invasive devices such as pacemakers, catheters, and prosthetic heart valves as well as smooth plastic and tissue surfaces. ${ }^{10}$ This mechanism is vital for the persistence of CoNS as biofilm-producing strains are characterized by greater resistance to antibiotics. Indeed, most invasive CoNS strains, which display biofilm formation, also show multidrug resistance, with $>80 \%$ of them being methicillin resistant. ${ }^{11}$

Associated with the pathogenicity of CoNS species is the possession of a host of virulence factors, encoded by specific genes that allow the pathogen to establish infection within the host. The atl $\mathrm{E}$ gene encoding the vitronectin-binding cell surface protein, which facilitates primary attachment and the

\footnotetext{
${ }^{1}$ Antimicrobial Research Unit, College of Health Sciences, University of KwaZulu Natal, Durban, South Africa.

${ }^{2}$ School of Laboratory Medicine and Medical Sciences and ${ }^{3}$ Biomedical Research Unit, University of KwaZulu Natal, Durban, South Africa.
} 
ica gene, encoding biofilm formation are examples of virulence genes possessed by pathogenic strains of CoNS. ${ }^{12}$ $S$. haemolyticus, S. epidermidis, and S. warneri have been found to produce hemolysins, which lyse susceptible cells to cause leakage of important molecules. ${ }^{1}$

CoNS, like $S$. aureus, have the ability to develop antibiotic resistance, increasing the cost of treatment and contributing to significant morbidity and mortality. ${ }^{13,14}$ Resistance to commonly used antibiotic classes such as macrolides, aminoglycosides, and to a last resort, antibiotics, such as the glycopeptides, has increasingly been reported in CoNS species. ${ }^{15-17}$ The sustainable effectiveness of glycopeptides against such resistant strains has become topical since the first recorded cases of teicoplanin resistance in methicillin-resistant coagulase-negative staphylococci (MR-CoNS) in the United States and the United Kingdom. ${ }^{18}$ Since then, glycopeptide-resistant CoNS in patients on prolonged vancomycin treatment have been variously reported, thus limiting therapeutic options. ${ }^{19}$

CoNS have a particularly high resistance against methicillin $(70 \%-80 \%)$ as indicated by various reports in the Canada, United States, and Latin America. ${ }^{20,21}$ CoNS possess a wide range of multidrug-resistant determinants mostly on plasmids that mediate resistance to some major antibiotics and can be transferred between different staphylococcal species such as $S$. intermedius and S. aureus. ${ }^{19}$ For instance, horizontal transmission of the mecA gene (which mediates methicillin resistance and is carried by the mobile genetic element $S C C \mathrm{mec}$ ) to other staphylococcal species has been suggested to be a common occurrence. ${ }^{22}$

As at 2018, there were 54 species and 28 subspecies comprising the genus staphylococcus, ${ }^{23}$ whereas 41 CoNS species have been documented as of July $2018 .^{24}$

CoNS are not only problematic pathogens in human medicine, but also cause several infections in animals, particularly in livestock production with resultant economic losses. Globally, CoNS are a known leading cause of mastitis, particularly in Europe. ${ }^{25}$ Having been considered opportunistic pathogens, which cause mild mastitis that usually remains subclinical, their importance in intramammary infections (IMIs) is increasing as CoNS species have been frequently isolated from most IMIs. ${ }^{26}$ Also, no $<24$ CoNS species have been identified in cases involving bovine mastitis. ${ }^{27}$ Genetic typing methods, such as $S C C$ mec typing and multilocus sequence typing (MLST), are essential to relate circulating clones/types to pathogenicity. ${ }^{28}$

Concerning CoNS in Africa, there is a dearth of information about their prevalence, epidemiology, role, and antibacterial susceptibility in human and animal (mainly livestock) diseases. Thus, this review seeks to gather information concerning clinically relevant CoNS species in humans and animals in Africa within the last decade. We herein discuss studies from Africa where CoNS species were suspected as the cause of various infections, focusing on identification/laboratory detection, their clinical relevance, transmission, antibiotic susceptibility, typing, and treatment.

\section{Identification/laboratory detection of CoNS}

It is important to distinguish between coagulase-positive staphylococci and CoNS as a basic principle, a practice carried out in most laboratories by the slide and tube coagulase tests. Identification down to species level is important particularly for species suspected to cause infections and informs accurate clinical decision making by clinicians. Correct speciation of CoNS is important in detecting exact causes of infection in nosocomial setting in particular, where appropriate, dependable, inexpensive, and fast identification methods are required for effective diagnoses and prompt treatment. ${ }^{22}$ This is mostly achieved by biochemical tests, including commercially available kits. ${ }^{29}$ Due to the similar biochemical characteristics exhibited by various CoNS species and species heterogeneity, correct identification by biochemical tests is often challenging. Furthermore, biochemical methods are laborious. ${ }^{26}$

Speciation with biochemical methods is gradually being replaced by molecular methods such as polymerase chain reaction (PCR) and spectrometric methods, such as matrixassisted laser desorption/ionization time-of-flight mass spectrometry (MALDI-TOF MS). ${ }^{29}$ Thus, molecular methods which offer a higher level of precision in identification up to species and subspecies level are advocated where appropriate. However, with molecular methods, where sequence data analysis is involved, there may be challenges with sequence data analysis when poor quality sequence data are deposited into databases. ${ }^{29}$

Mostly, species identification is not carried out and they are frequently reported as a general group, thus limiting information available on their epidemiology and downplaying the actual influence of the various, particularly nonabundant species. ${ }^{30}$ MALDI-TOF MS as an identification technique also has a useful application in toxin detection and has been shown to exhibit high accuracy and reproducibility when used to identify $\mathrm{CoNS}^{26}$ Other strengths of MALDI-TOF MS lie in its quick turnaround times and low operating costs. However, the initial cost of the instrument is expensive and cannot be afforded by many laboratories, especially in low- and middle-income countries. Furthermore, MALDI-TOF has been reported as unable to detect rare species in close to $50 \%$ of cases. ${ }^{31}$

In such cases where rare species are suspected, sequencing of phylogenetically important target genes such as the $16 \mathrm{~S}$ rRNA gene can prove useful. ${ }^{31}$ Indeed, amplification and sequencing of target housekeeping genes such as elongation factor $\mathrm{Tu}$ (tuf) gene, superoxide dismutase $(\operatorname{sod} A)$, RNA polymerase B $(r p o B)$, and $16 \mathrm{~S}$ rDNA gene have been shown to assist in discriminating between Staphylococcus species and subspecies with varying levels of discriminatory power. ${ }^{32,33}$ Molecular methods such as PCR affords higher accuracy, typeability, and reproducibility and are therefore recommended in CoNS speciation. ${ }^{26,34}$

More than half of studies considered in this review used basic culture and standard biochemical tests in identification, hence did not have the wherewithal to identify CoNS to the species level. Multiplex PCR, MALDI-TOF MS, and tuf gene sequencing were used for the speciation of CoNS by Schmidt et al. while investigating distribution and antimicrobial susceptibility profile of Staphylococcus species isolated from cattle with IMIs and humans working in close contact with them. ${ }^{26}$ The multiple approach to pathogen identification improves the accuracy of identification up to species level.

With the decreasing costs of next-generation sequencing techniques, there could be a shift from phenotypic- to genome-based diagnoses of infections. The shift is a major boost in the search for known and emerging resistance determinants because whole genome sequencing (WGS) 
provides all the information required to make informed diagnostic decisions, including the species of the offending pathogen, antibiotic resistance genes (ARGs), evolution, and spread of pathogens. ${ }^{35}$ Furthermore, WGS furnishes researchers with additional data not currently provided by routine diagnostic methods or even by molecular techniques such as PCR. WGS can be used to predict antibiotic resistance phenotypes by investigating resistance determinants at the genomic level, thus helping clinicians to make rapid clinical decisions to improve patient care. ${ }^{34,35}$ Although, molecular methods such as PCR have been used with great success, WGS, by looking at the entire genome offers an improvement in explaining the genetic and epigenetic mechanisms of observed phenotypic resistance. For example, the observation of phenotypic resistance without the detection of classical or known resistance genes by PCR is solved by WGS, by looking at the entire genome, including genetic changes in the genome which may contribute to the observed resistance. ${ }^{35}$ Furthermore, the computational sequence querying used by WGS may be more sensitive than primers used in PCR. The challenges, however, lie in the analysis and interpretation of results, the lack of universality of data analysis platforms, and the large computer memory sizes required for the processing and storage of genomic data. ${ }^{36}$

\section{Epidemiology and clinical relevance}

The skin as a barrier provides a protective function. It is inhabited by a plethora of varied microorganisms with CoNS being a commensal of the skin and mucosal microbiota of humans and animals. ${ }^{37}$ Studies of the skin metagenome have buttressed the long-known assertion that Staphylococcus species have a preference for areas of higher humidity such as the plantar foot region, axillae, and umbilicus. ${ }^{38}$ The $S$. epidermidis group (consisting of $S$. epidermidis and S. haemolyticus) are the most commonly isolated CoNS species in humans, usually found in moist areas of the skin. ${ }^{37}$

A great challenge when dealing with clinical CoNS is to determine their clinical relevance. Clinicians and microbiologists are frequently faced with determining whether retrieved CoNS are contaminants that intrude during sampling or sample processing, are regular skin or mucous membrane commensals, or are clinically relevant. ${ }^{30}$ Because many CoNS species form part of the skin and mucous membrane microbiota, the line between innocuousness and pathogenicity may be indistinct and comes down to virulence strategies employed by the various species as well as host defense mechanisms. Having been considered largely nonpathogenic, the pathogenicity of CoNS had been acknowledged by the 1980s, although there were not enough advanced techniques to delineate their molecular mechanisms. ${ }^{30}$

The significance of CoNS in causing infections is highly recognized in certain vulnerable populations such as the immunocompromised, preterm newborns, the elderly, critically ill, and long-term hospitalized patients as well those with invasive devices. ${ }^{39}$ A high number of CoNS in samples may be attributed to contamination that occur during sampling, in which case techniques to minimize contamination are required. However, CoNS may be the true cause of infection and need to be assessed. The ability of commensals to cause infections differ. ${ }^{40}$

The difficulty in determining the pathogenicity of most CoNS samples, including clinical samples, is due partly to poorly defined virulence factors in these strains even though the possession of some genetic markers could prove important in distinguishing between potentially virulent and saprophytic/contaminating strains of CoNS. ${ }^{19}$ The possession for example of virulence factors, such as Panton-Valentine leukocidin or toxic shock syndrome toxin 1 and enterotoxins could be associated with increased pathogenicity of CoNS. ${ }^{41}$ The CoNS do not possess as many virulence factors as $S$. aureus, reflected in the different spectra of diseases they respectively cause. ${ }^{41}$ The detection of phenol-soluble modulins in S. epidermidis was found to contribute to endemicity, invasiveness, and persistence in hospital environments ${ }^{42}$ and CoNS sepsis, especially when methicillin resistant. ${ }^{43}$

In a study investigating factors that contribute to the pathogenicity of CoNS from clinical sources in comparison with community CoNS strains, it was found that $25 \%$ of strains produced toxins that induced hemolysis in 50\% of human red blood cells within 1 hour, with some $3 \%$ showing lytic activity on human polymorphonuclear cells after 30 minutes. ${ }^{44}$ The staphylococcal enterotoxin C gene was detected in $9 \%$ of $S$. epidermidis strains using latex agglutination and PCR methods. When compared with community strains (32\%), $68 \%$ of hospital-associated CoNS strains had at least one virulence determinant in that study. ${ }^{44}$ The production of exoenzymes and extracellular enzymes enables disruption of host tissues to stifle the immune system, thus helping the organism to establish infection. For example, elastase produced by S. epidermidis, damages fibronectin, albumin, and fibrinogen. 45

Specifically, identification of true bacteremia from contamination is complicated, as there is no single benchmark with adequate level of specificity. Certain parameters have been used such as the number of positive blood cultures for CoNS obtained, correlated with clinical symptoms. ${ }^{28}$ Studies have linked the detection of at least two positive blood cultures with clinical bacteremia; that is, CoNS were thought to play pathogenic roles if multiple positive blood cultures were obtained within a specific period. However, it has been found that about $34 \%$ of bacteremia of nosocomial origin had only one positive blood culture. ${ }^{28}$ Thus, the sole use of this parameter may lead to underdiagnoses of clinical bacteremia due to CoNS.

Mvalo et al. considered CoNS as a cause of bloodstream infections (BSIs) and not a contaminant if they were isolated from at least two blood cultures within a 48 -hour period. ${ }^{46}$ Ballot et al., investigating BSIs of bacterial origin in neonates, considered CoNS as contaminants if only there were no clinical signs of illness, C-reactive protein (CRP) was normal, and there was no indwelling device. ${ }^{47}$ Similar parameters like multiple blood cultures of same microorganism isolated from distinct sites within 7 days of initial culture, with corresponding suggestive inflammatory markers (such as increased CRP and white cell count) have been used. ${ }^{48}$

Other indicators for determination of true bacteremia include identifying the CoNS species involved, the biotypes, antimicrobial susceptibility, and clonality. For instance, when recovered CoNS species are identical or are highly clonally related, there could be a decreased possibility of contamination and may reflect true bacteremia. ${ }^{28}$ Thus, increased capacity for species identification and typing is required. Advances in molecular and phenotypic techniques, including WGS and spectrometric methods, have largely contributed to an understanding of mechanisms of pathogenicity. Most commonly reported CoNS species implicated 
in infections in this review are $S$. epidermidis, $S$. haemolyticus, and S. xylosus (Tables 1 and 2 and Fig. 1). Other CoNS species recovered in the various studies reviewed herein include $S$. lugdunesis, S. capitis, ${ }^{49}$ S. saprophyticus, S. simulans, ${ }^{1}$ S. hominis, ${ }^{22}$ S. warneri, S. cohnii urealyticum, and $S$. sciuri. ${ }^{50}$ It is apparent that there is a pronounced species diversity of CoNS in Africa.

The adherence to a host or surfaces of invasive devices is a vital process deployed by staphylococci to colonize host and/or establish infection. CoNS colonize the polymer surfaces of devices by forming biofilms of multiple layers. ${ }^{51}$ This process is vital in the pathogenesis of infections associated with invasive devices. ${ }^{30} \mathrm{~S}$. epidermidis, of the CoNS species, is most frequently isolated from biofilm-associated infections. ${ }^{52}$ The organisms most likely gain entry during the insertion of device through the skin or mucous membranes. In biofilms, there is the agglomeration of bacterial cells enclosed in vague extracellular material containing bacterial products such as polysaccharides, teichoic acids, extracellular DNA, and proteins. ${ }^{52,53}$

Biofilms can form on living (such as host tissues) surfaces or nonliving (such as medical devices) surfaces. Considering that biofilm formation is the most important factor in CoNS pathogenesis and virulence, ${ }^{42}$ it is important for studies to investigate the phenomenon in CoNS to inform clinicians of its possible role in virulence. Phenotypic methods, genotypic detection of biofilm-formation genes (by PCR), or WGS are handy in this regard.

Pathogenic conversion of CoNS, where the simultaneous possession of coa, $v w b$, and clfA genes (encoding coagulation and agglutination of vertebrate blood) by CoNS was observed to have enhanced the survival of $S$. simulans in whole blood and replication in distal organs due to enhanced ability to agglutinate in plasma. ${ }^{54}$ Thus, the possession of these determinants has been mooted as a possible mechanism of converting otherwise commensal staphylococci into invasive pathogens. ${ }^{54}$

Although determining the pathogenicity of CoNS can be difficult, signs of inflammation, inserted foreign body, immunosuppression, virulence determinants, and recurring detection of the same clone are generally factors that predict a high probability of infection rather than contamination. ${ }^{24}$

\section{Transmission}

Within the hospital, other health care facilities, and in animals, little is known about the transmission of CoNS and their outbreak potential. Multidrug resistance in CoNS, their ability to form biofilm, increased use of antibiotics and antiseptics, and the rising use of invasive devices may contribute to the transmission in these environments. ${ }^{55,56}$ The unsolved cases of transmission attributed to circulating clones of CoNS may be underreported as many CoNS outbreak cases are unidentified. In vulnerable populations such as the immunocompromised, their contribution to significant morbidity and mortality have been acknowledged. ${ }^{30}$

\section{Occurrence, Role, and Antibiotic Susceptibility of Suspected Clinically Relevant CoNS in Humans, Within Africa, Since 2009}

\section{Bloodstream infections}

In a retrospective crosssectional study conducted to investigate the epidemiology of bloodstream infections (BSIs) among pediatric oncology patients in South Africa, $49.1 \%$ of blood-positive cultures identified were Gram-positive isolates, of which CoNS represented $23.1 \%$, even though the BSIs found were generally associated with a low-case fatality rate (Table 1). ${ }^{46}$ Indeed, Gram-positive bacteria are responsible for up to about $70 \%$ of neonatal nosocomial infections in many hospitals, with CoNS accounting for more than half of infections represented in Fig. 2. ${ }^{57,58}$ However, Gram-negative pathogens may be more dominant as causes of neonatal infections in low- and middle-income countries, with higher rates of antibiotic resistance. ${ }^{59} \mathrm{Op}$ portunistic infections are a significant contributor to morbidity and mortality in pediatric oncology. The frequent use of indwelling central vascular access devices and the recurrent hospitalizations in cancer patients present an increased risk of exposure to pathogenic CoNS, leading to increased infections, which are usually multidrug resistant. ${ }^{46}$

A similarly high CoNS prevalence of $19.1 \%$ was recorded as a cause of BSI in neonates in a South Africa study, with $86 \%$ of them showing methicillin resistance (Table 1). ${ }^{47}$ The vulnerability of immune systems of neonates makes them susceptible to infections, not least among them is neonatal sepsis, an infection which upon presentation may be hard to establish and is also linked with significant morbidity and mortality. ${ }^{47,57}$ Thus, early initiation of empirical antimicrobial therapy, on suspicion of neonatal sepsis, is critical, until the condition is ruled out or the actual cause of infection is determined. The observed susceptibility patterns of bacteria to antibiotics informs the choice of empiric antibiotic treatment. Empiric antimicrobial therapy should be tailored as pathogenic causes and sensitivities of infections vary between neonatal units. No vancomycin resistance was observed in Gram positives on susceptibility testing in this study. ${ }^{47}$ Thus, vancomycin will be useful as empiric treatment for CoNS sepsis, including MR-CoNS in this setting.

In a neonatal intensive care unit (ICU) in South Africa, CoNS were rated third (19\%), behind Acinetobacter $(21 \%)$ and Klebsiella (25\%) as the cause of significant BSI events (Table 1). ${ }^{48}$ BSIs (neonatal sepsis) are a significant cause of morbidity and mortality in neonatal ICUs around the world. In low/middle-income countries, there is a paucity of data on BSI in neonatal ICUs, and the menace of BSIs is compounded by the limited human and physical resources in these areas, as compared with high-income countries, where bloodstream pathogens are well described. ${ }^{60}$

The occurrence of multidrug resistance in CoNS presents a peculiar problem in resource-constrained countries due to lack of access to newer generation antibiotics, which are also more costly. In low/middle-income countries, an estimated $50 \%-78 \%$ of neonatal BSIs are caused by Gram-negative pathogens. ${ }^{61}$ As well, in Zambia, CoNS was second $(6 \%)$ only to Klebsiella species $(75 \%)$, as the cause of neonatal sepsis in neonatal ICU of a referral center in a study that investigated the etiology of neonatal sepsis. ${ }^{62}$

CoNS were found among the leading etiologies of confirmed neonatal sepsis at $12.6 \%$, coming third after $S$. aureus $(31.0 \%)$ and Klebsiella $(23.0 \%)$, in Nigeria (Table 1), with isolates showing susceptibility toward levofloxacin $(95.7 \%)$, ofloxacin $(95.1 \%)$, cefotaxime $(86.7 \%)$, and ceftazidime $(81.3 \%) .{ }^{63}$ However, against the commonly used gentamicin and cefuroxime, $56.4 \%$ susceptibility was observed. There was a high rate of susceptibility to quinolones, although this 
|

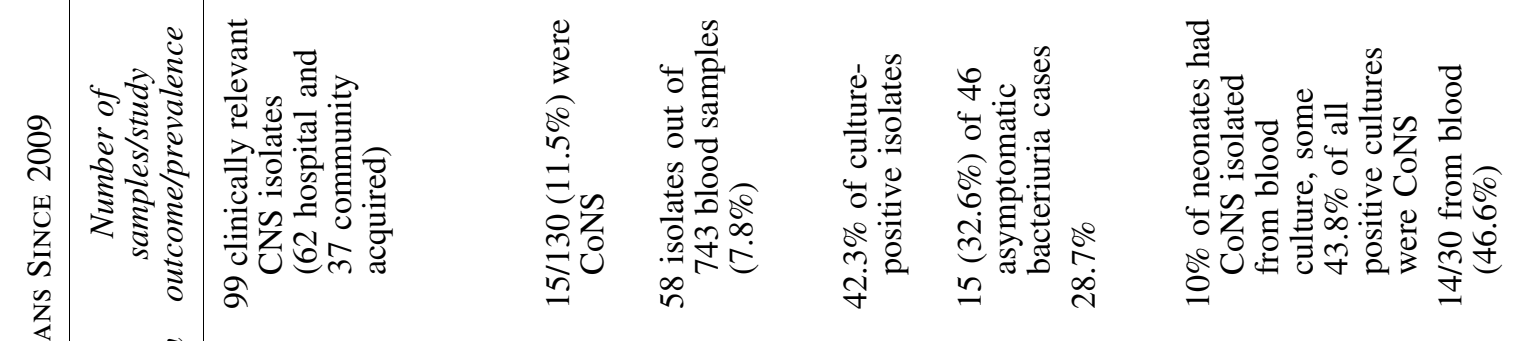

党

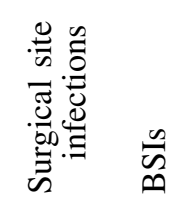

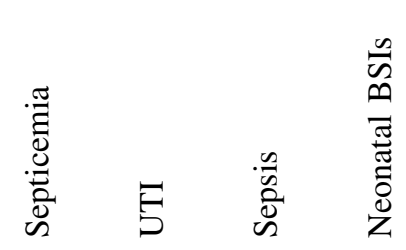

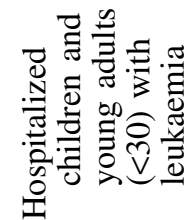

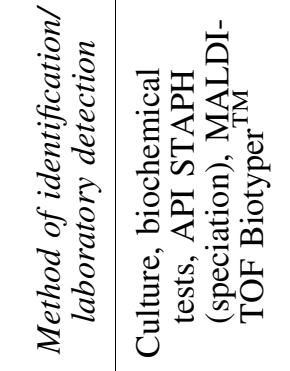
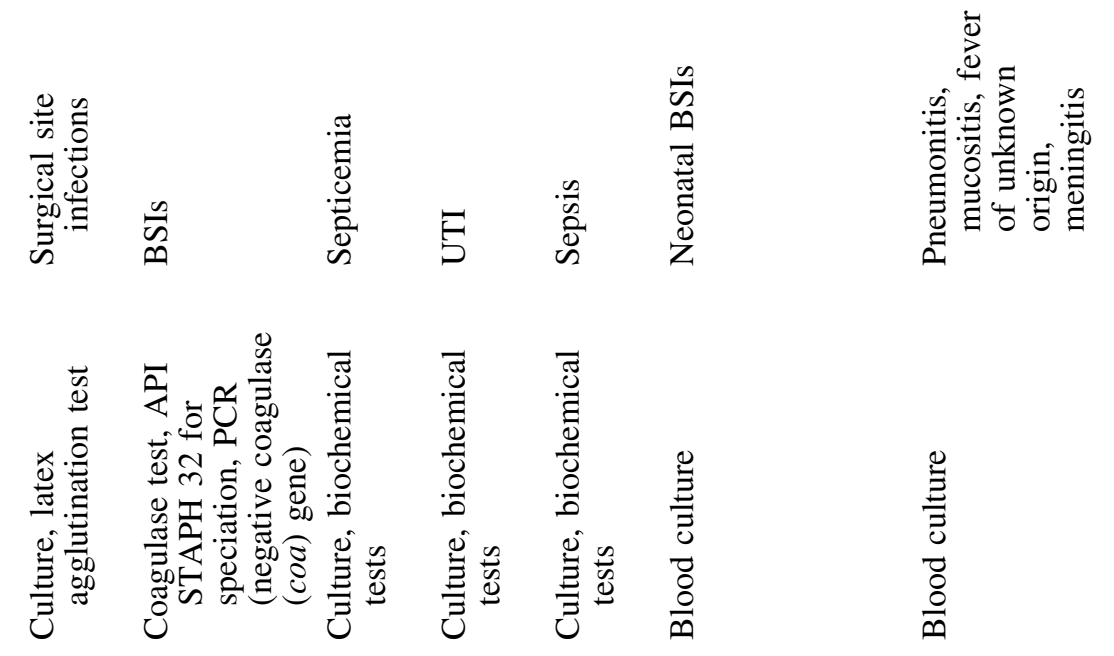

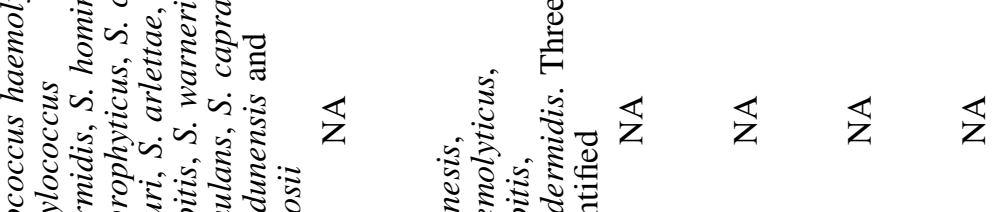

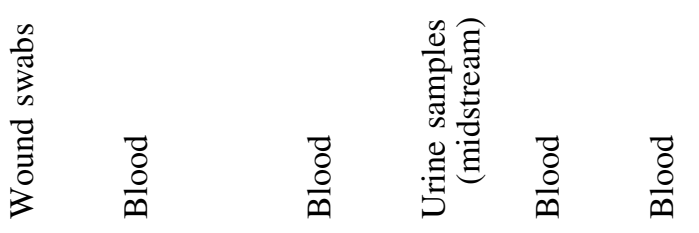

$\frac{\stackrel{0}{\Xi}}{\frac{0}{0}}$ 


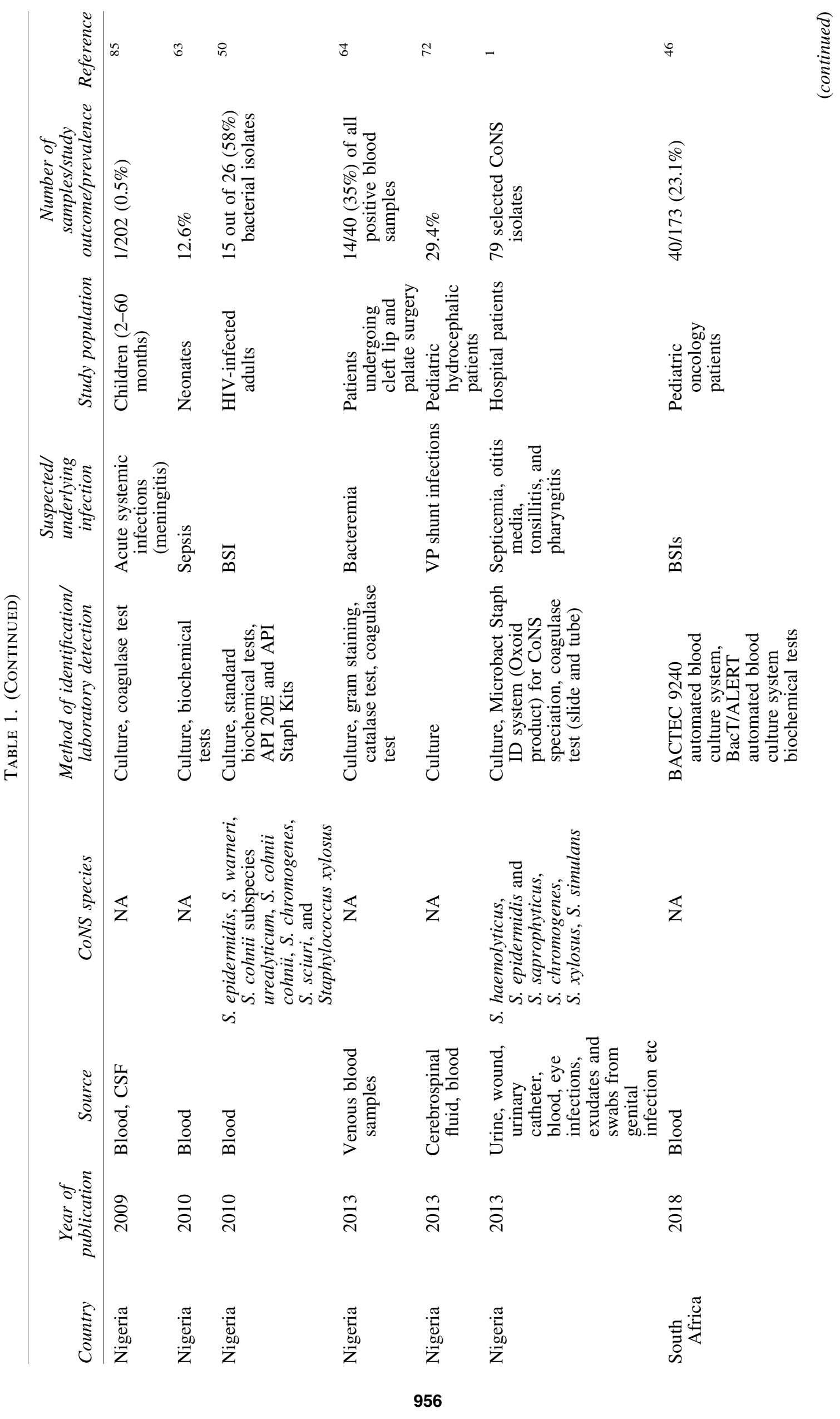




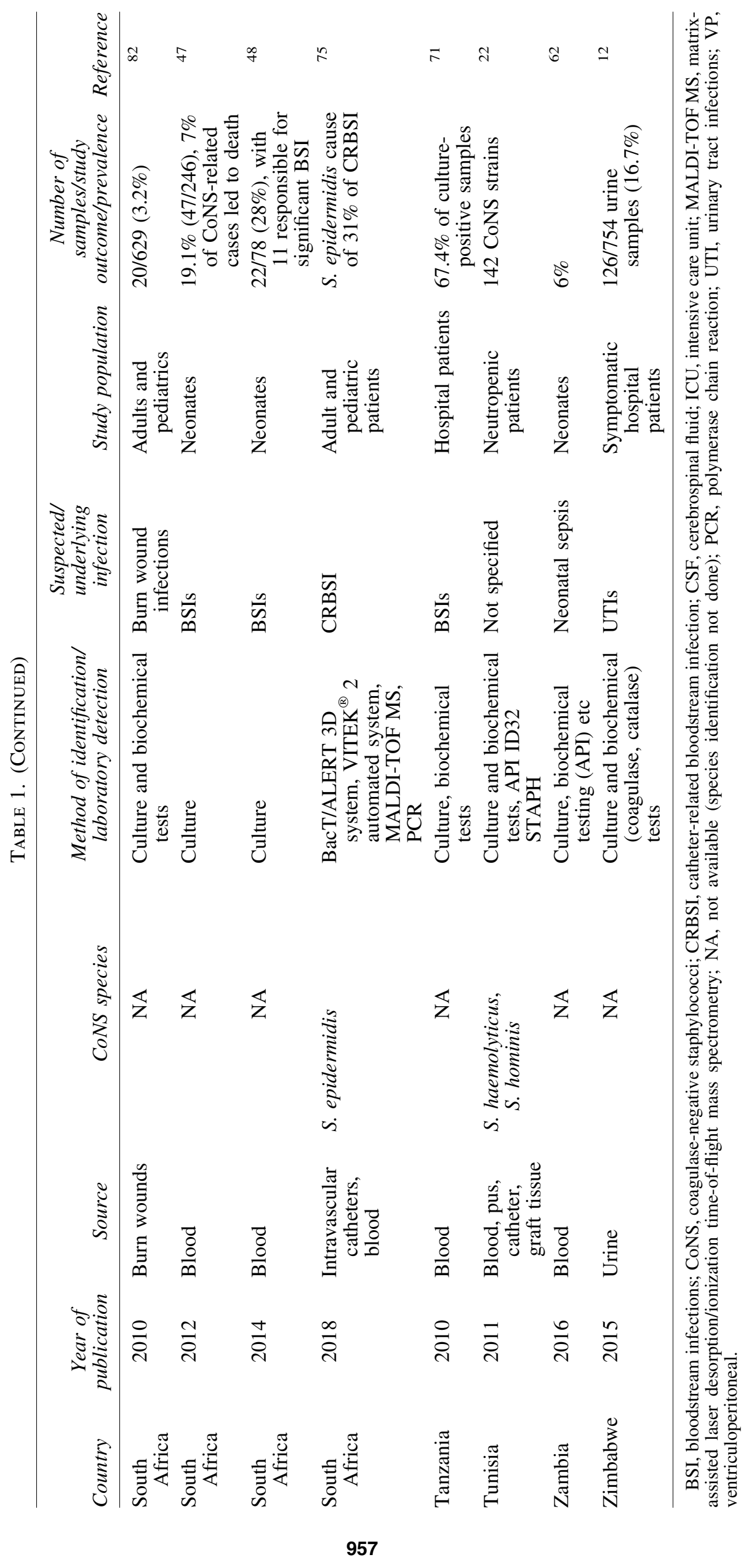




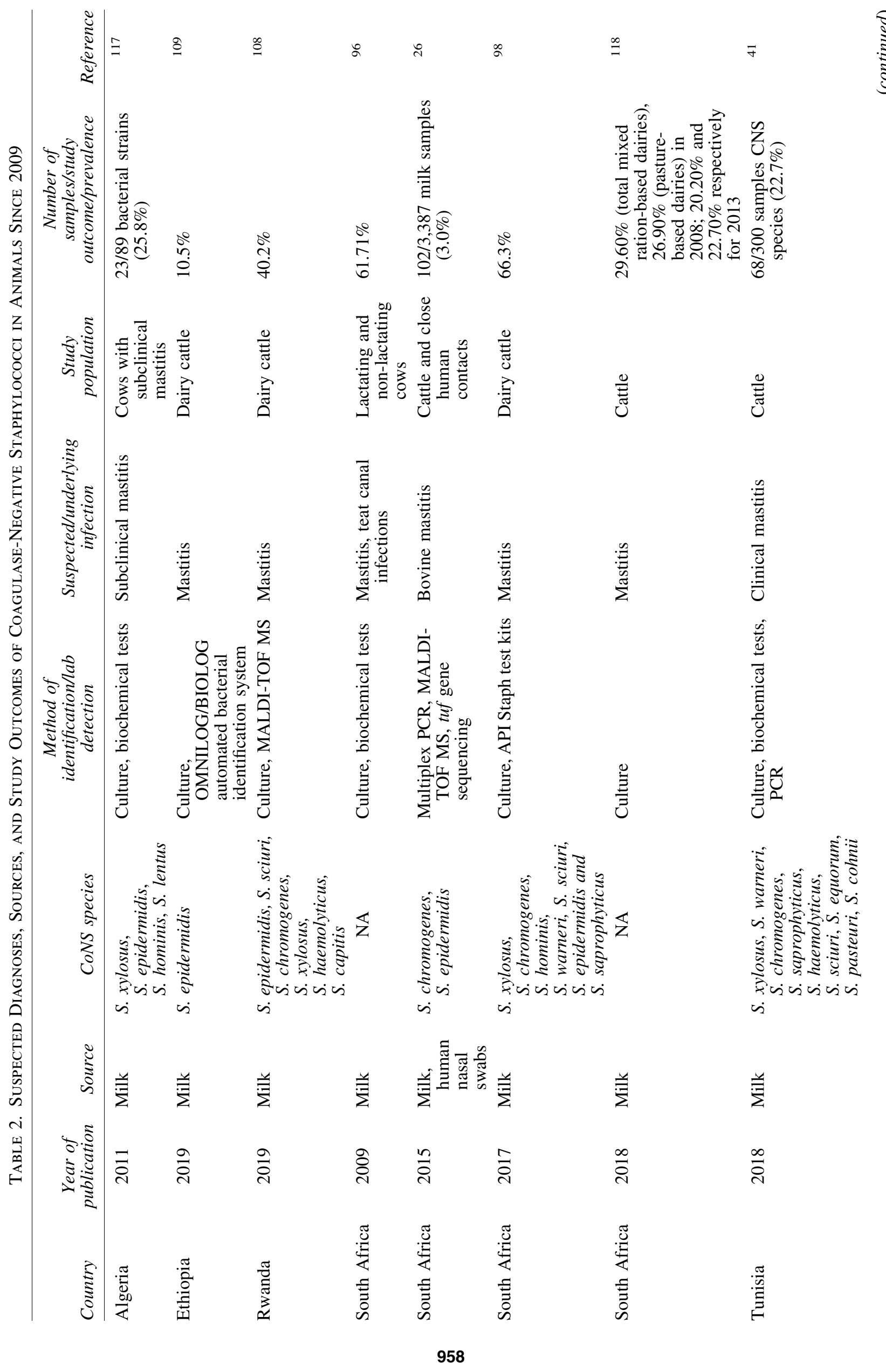




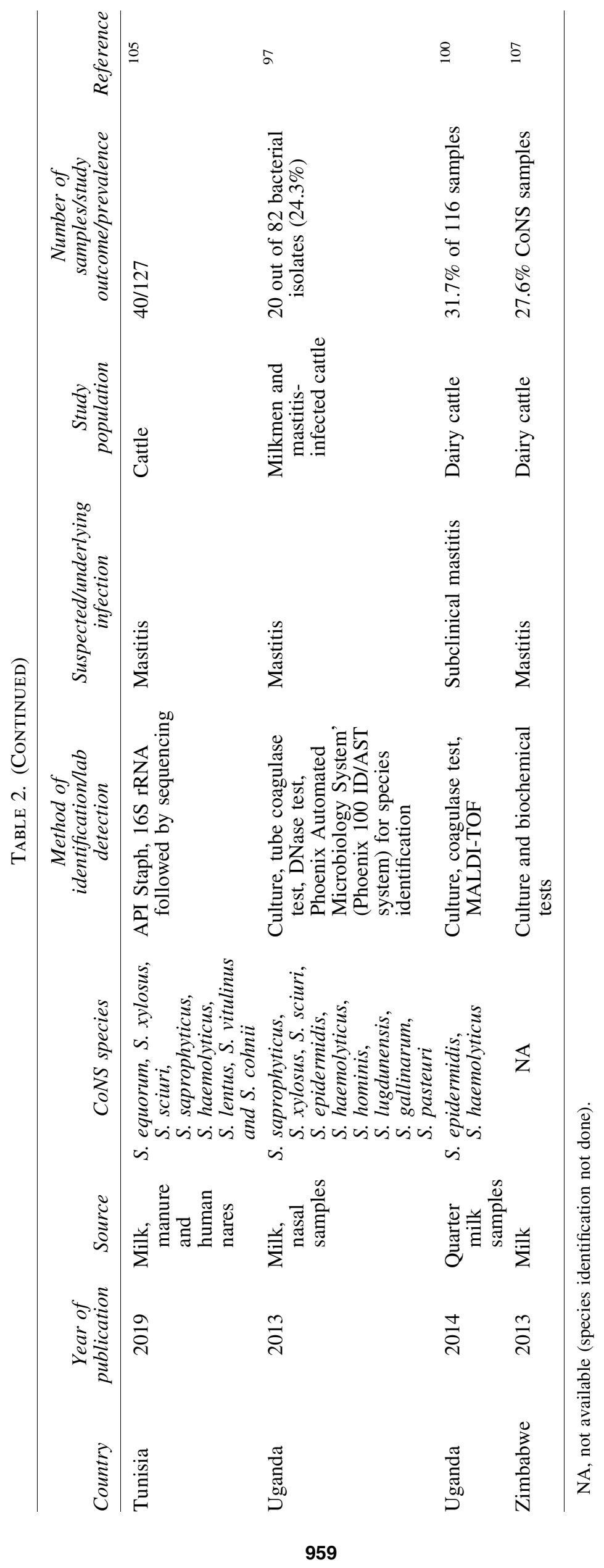




\section{Frequency of CoNS species in studies in Africa}

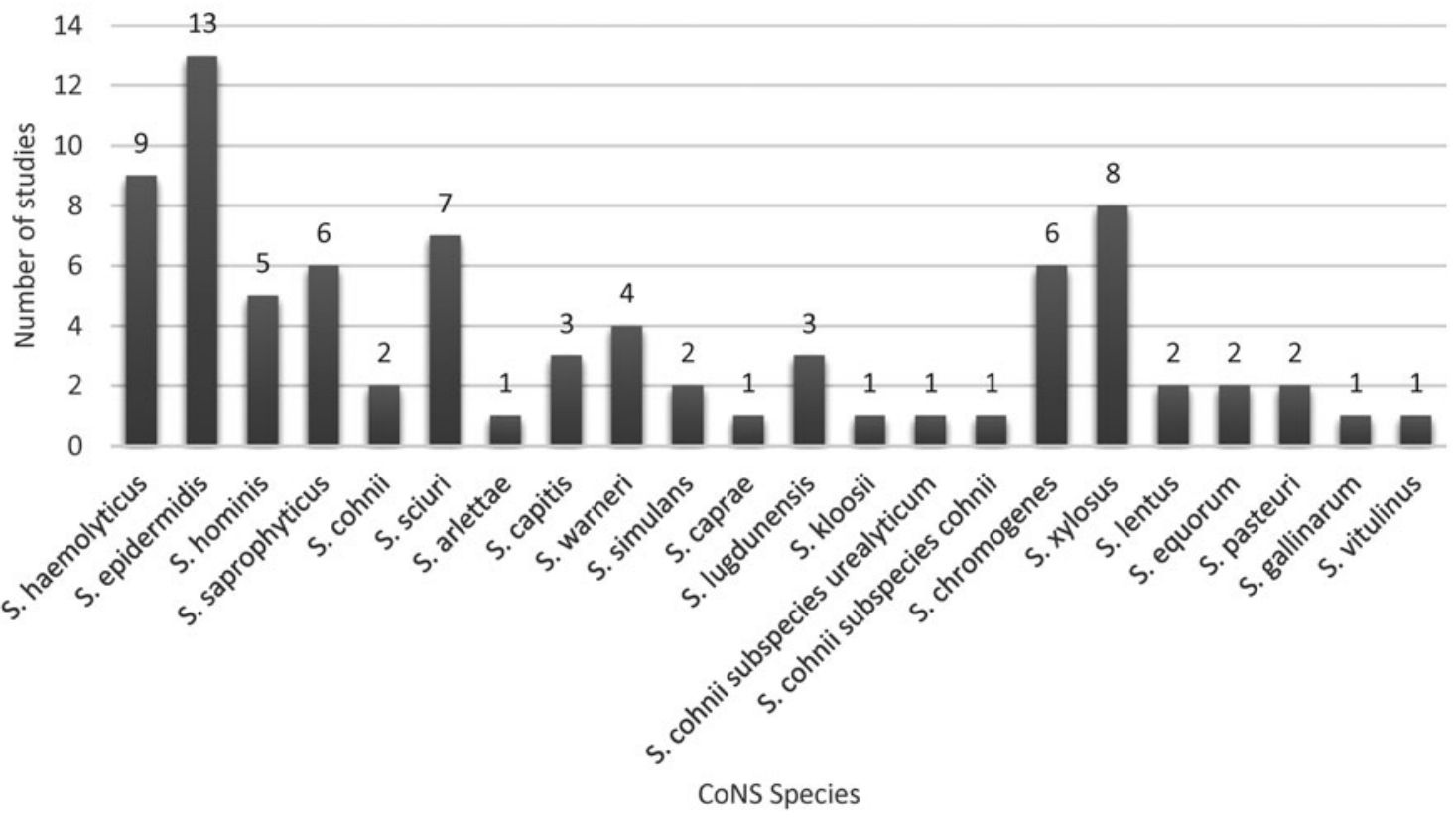

FIG. 1. A graph showing the frequency of CoNS species according to the number of studies in the last decade. CoNS, coagulase-negative staphylococci.

class is reportedly unsafe for newborns. Prompt empirical treatment based on likely etiology and observed susceptibility patterns is useful, as results from laboratory investigation may not be available between 48 hours and 7 days.

The reduced susceptibilities toward commonly used antibiotics such as cefuroxime (37.5\%), ampicillin (37.5\%), cloxacillin (15.4\%), and amoxicillin/clavulanic acid (47.4\%) in that study setting, is worrying as the focus of clinicians will be shifted to deploy newer generation antibiotics, with increased cost of treatment. Furthermore, the increased use of newer generation or last-resort antibiotics selects for the development of resistance, which becomes problematic especially when bacteria disseminate ARGs to hitherto susceptible bacteria. Patients with poor perinatal events need to be monitored carefully and treated until sepsis is ruled out especially those with high risk factors such as low birth weight, low socioeconomic status, protracted labor, and prolonged rupture of membranes. ${ }^{63}$

CoNS was implicated in $35 \%$ of positive blood samples as a cause of bacteremia in patients undergoing cleft lip and palate surgery (Table 1). ${ }^{64}$ As Staphylococcus species are usual colonizers of the skin and nasal passages, incisions made during cleft repair surgery cause the otherwise commensals to encounter mucous membranes of skin and nasal passages. Thus, Staphylococcus species, and particularly CoNS in this study, may enter the bloodstream through contaminated cleft lip and palate wounds. ${ }^{64}$ Even though CoNS were the most commonly isolated pathogens, cases of bacteremia associated with cleft lip and palate surgery were polymicrobial in nature, due to the polymicrobial nature of the oral cavity, necessitating the use of broad-spectrum antibiotics for prophylaxis and treatment in vulnerable groups. ${ }^{64}$

Among HIV-infected adults consecutively attending HIV clinic at a tertiary-level teaching hospital in Nigeria, a CoNS prevalence of $58 \%$, ahead of Gram-negative nontyphoid
Salmonella spp (23\%) and Salmonella typhimurium (15\%), was found as cause of bacterial BSIs. ${ }^{50}$ Antimicrobial susceptibility testing showed that CoNS isolates displayed high or complete susceptibility to ceftazidime $(66 \%)$, cefotaxime (66\%), amoxicillin/clavulanic acid (100\%), cefuroxime $(73 \%)$, piperacillin/tazobactam $(100 \%)$, oxacillin $(100 \%)$, and vancomycin $(100 \%)$, but mainly showed resistance against ampicillin $(73 \%)$, tetracycline (53\%), and penicillin (73\%). BSIs have been frequently associated with HIV/AIDS patients and are estimated to account for significant morbidity and mortality within this population. ${ }^{50}$ Considering that HIV/AIDS patients have compromised immune systems, the presence of CoNS as a leading cause of BSIs is unsurprising as it has been established that CoNS species are a leading cause of infection in immunocompromised patients. ${ }^{65}$

Vancomycin heteroresistance in CoNS BSIs in ICU patients was investigated in a study that found a CoNS prevalence of $7.8 \%$ as probable cause of BSIs, of which $75.9 \%$ were oxacillin resistant. ${ }^{49}$ Genotypic detection by PCR found all oxacillin-resistant isolates contained the mecA gene. Vancomycin heteroresistance in CoNS isolates was detected by population analysis profile even though all CoNS isolates were susceptible to vancomycin. This observation presents a growing health concern. Thus, stricter screening methods are recommended to detect them and improve treatment outcomes of patients. CoNS are major culprits in the bacterial etiology of BSIs in ICU patients. ${ }^{66}$ Because of the increasing resistance toward $\beta$-lactam antibiotics in CoNS, clinicians rely on glycopeptides (particularly vancomycin) as first-line antibiotics in the treatment of severe infections caused by CoNS. ${ }^{67}$

Whereas CoNS are considered as major neonatal pathogens in upper and high-income countries, little is known about their epidemiology, role, and coverage for empiric anti-Staphylococcal treatments in Africa. ${ }^{68}$ 


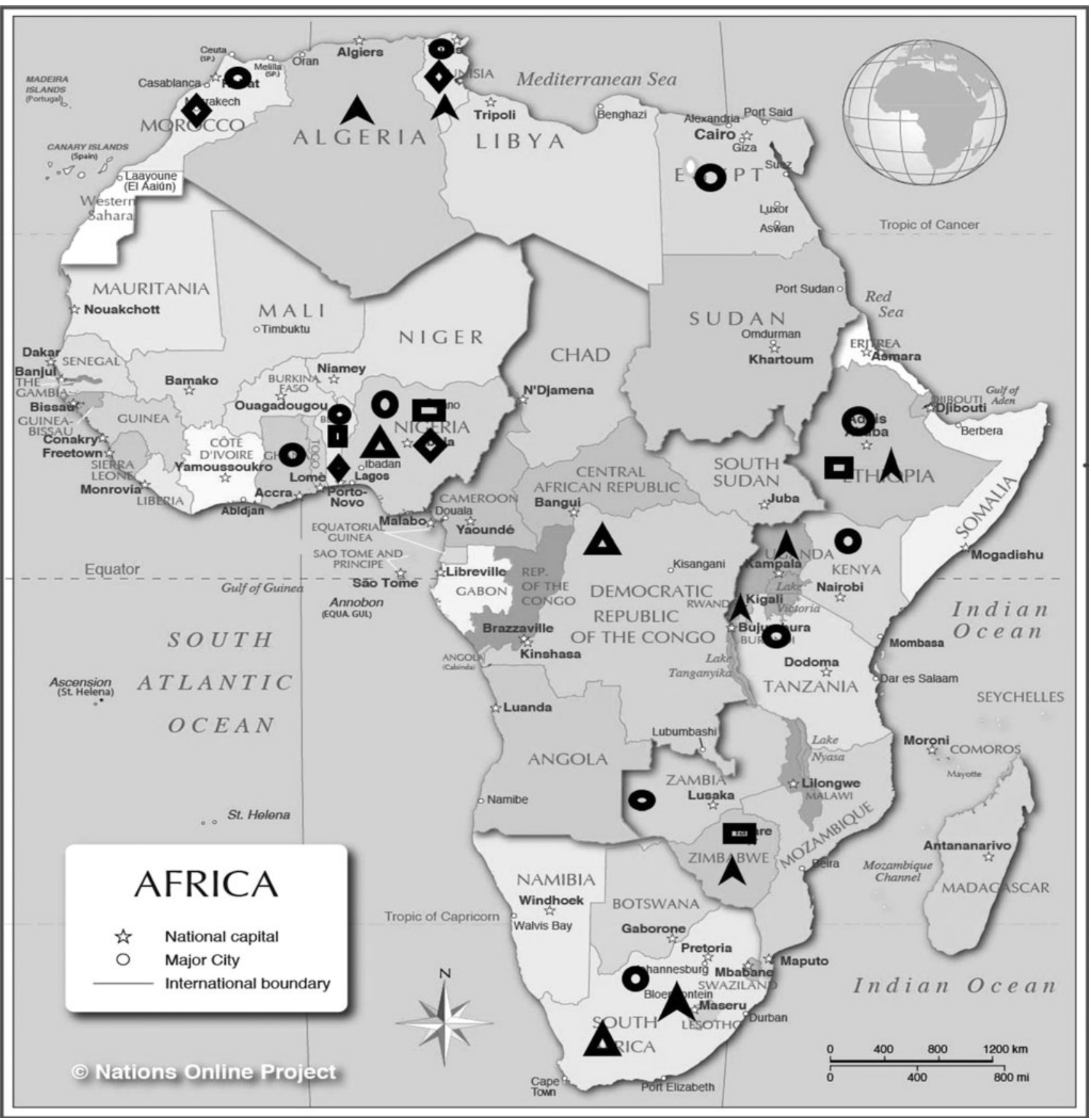

FIG. 2. Geographic distribution of CoNS infections in Africa between 2009 and 2019 (Map was reproduced from Nations Online Project). Map of Africa showing countries where CoNS were reported from 2009 to 2019. Most represented countries were Nigeria and South Africa. $\mathbf{O}$, bloodstream infections; $\boldsymbol{\square}$, urinary tract infections; $\boldsymbol{\Delta}$, wound infections; $\boldsymbol{\Delta}$, multiple source infections; $\mathbf{A}$, intramammary infections (cattle).

Seale et al. conducted a study to ascertain the prolonged duration of admission and case fatality rate of CoNSassociated neonatal infections in Kenya and observed no difference in case fatality rates between CoNS-associated infections and other infections (Table 1). ${ }^{68}$ Again, it was observed that CoNS did not lead to prolonged duration of hospitalization. Treatment protocol used by the hospital under study for neonates was in line with WHO guidelines, namely ampicillin and gentamicin as first line, and a thirdgeneration cephalosporin as second line. There was no spe- cific anti-Staphylococcal agent in the empirical treatment, although gentamicin may provide cover for staphylococcal isolates sensitive to methicillin. ${ }^{68}$

There may not be a distinct need to target staphylococci in empirical treatment in neonates, any more than would be considered for Gram-positive pathogens. Of critical importance, however, is to pay attention to the observed susceptibility patterns of antibiotics used empirically, while tailoring the need for changes. CoNS are more significant as a cause of infection after admission, and their role in infection may be 
understated depending on the time of sampling; late stage sampling may increase the significance of CoNS, which hitherto had been commensals. ${ }^{68}$ More invasive support techniques in neonatal practice may increase the significance of CoNS as important causative pathogens in resourceconstrained countries.

Varying incidence of $28.7 \%,{ }^{69} 42.3 \%,^{70} 67.4 \%,{ }^{71}$ and susceptibilities of CoNS in septicemia have been recorded in Ghana, Ethiopia, and Tanzania, respectively (Table 1). It is observable that there is a wide range of incidence of CoNS in BSIs from studies across Africa. The varying incidence could be due to geographical factors, sampling techniques, different laboratory detection capacities, among others.

\section{Invasive device-related infections}

CoNS were the most common etiology (29.4\%), ahead of S. aureus $(23.5 \%)$ and Escherichia coli $(11.8 \%)$ in a study conducted to investigate the contributing factors and outcomes of shunt infection in Nigeria (Table 1). ${ }^{72}$ Shunt infection was defined in the study as positive cerebrospinal fluid (CSF) with positive shunt component culture. Ventriculoperitoneal (VP) shunt is the main surgical procedure used in the treatment of hydrocephalus. However, the increase in VP-associated infections has caused significant morbidity and mortality in VP-treated hydrocephalic children, with the skin mostly the source of infection. ${ }^{72}$ The early detection and swift initiation of therapy are critical in the success of treatment of infections associated with VP shunts. The findings of the study agreed with general literature that CoNS and $S$. aureus are the most commonly reported causes of shunt infections. ${ }^{73,74}$ The formation of mucoid biofilms by CoNS favors their adherence to shunt hardware, thus enhancing their survival. Of significant note was that the mortality rate in patients with shunt infection was $21.4 \%$ as compared with $2.7 \%$ in those without shunt infection. ${ }^{72}$ Treatment of CoNS in invasive device-related infections has been discussed under "treatment" section.

Bouchami et al. found that $31 \%$ of the total CoNS isolates were from catheters, ${ }^{22}$ whereas foreign body-related infection accounted for $1 \%$ of CoNS infections in a Benin study. ${ }^{44}$

Ehlers et al. while investigating catheter-related bloodstream infections (CRBSI) in a South African hospital, determined S. epidermidis as the cause of infection in $31 \%$ of CRBSI with isolates displaying complete resistance to $\beta$-lactams and high resistance to gentamicin $(81 \%)$ and erythromycin $(86 \%)$. The study also showed that $81 \%$ of $S$. epidermidis isolates carried the $q a c \mathrm{~A} / \mathrm{B}$ and ica $\mathrm{AB}$ genes each.

\section{Urinary tract infections}

CoNS have emerged as a principal cause of UTIs especially among immunocompromised and hospitalized patients with the high occurrence of hospital-acquired UTIs attributed to the use of urethral catheters. ${ }^{5}$

The occurrence of asymptomatic bacteriuria and antibiotic susceptibility in pregnant women seeking antenatal care in an Ethiopian teaching hospital was studied, and found CoNS to be responsible for $32.6 \%$ of asymptomatic bacteriuria cases, compared with $26.1 \%$ for $E$. coli and $13 \%$ for $S$. aureus (Table 1). ${ }^{76}$ Infections were mostly polymicrobial, with the highest proportion of polymicrobial infection recorded for CoNS and E. coli at $8.7 \%$. Previous studies about asymp- tomatic bacteriuria in pregnant women in Ethiopia have reported incidences of $7 \%-10.6 \%$, with E. coli, S. aureus, Klebsiella species, and $S$. saprophyticus frequently implicated. ${ }^{77,78}$ Thus, the incidence of asymptomatic bacteriuria in pregnant women in Ethiopia may be rising and steps need to be taken to reduce the risk of complications and perinatal events. Screening for asymptomatic bacteriuria, particularly commonly implicated bacteria, like CoNS, will enable early detection and forestall the development of complications.

The antibiotic susceptibility patterns and virulence factors of CoNS bacteria associated with UTIs was studied in Zimbabwe, where high resistance rates were found against oxacillin $(69.8 \%)$, cotrimoxazole $(72.2 \%)$, and nalidixic acid $(88.1 \%)$, while showing high susceptibilities toward gentamicin $(68.3 \%)$ and nitrofurantoin $(79.4 \%) .{ }^{12}$ The mecA gene (methicillin resistance) was detected in $62.5 \%$ of the CoNS isolates. The ica AB genes (encoding biofilm formation) and atl $\mathrm{E}$ (encoding the vitronectin-binding cell surface protein which facilitates primary attachment) were detected in $32.5 \%$ and $25 \%$ of isolates, respectively. The ica gene has been found as the most commonly detected virulence gene in CoNS highlighting the importance of biofilm formation in the virulence of pathogenic CoNS. ${ }^{12}$

The multidrug resistance profile of biofilm producers was underscored by the observation that 9 out of the 13 ica $\mathrm{AB}$ gene-positive isolates (which also possessed the mecA gene) were resistant to most of the antibiotics tested in the study, although no direct relationship between ica AB gene detection and resistance was established. What was apparent though, was the association between biofilm formation and multidrug resistance. Furthermore, the detection of ica AB and $m e c A$ genes, may be an important determinant to differentiate between infectious and innocuous strains of CoNS. ${ }^{12}$

S. haemolyticus (29\%), S. saprophyticus (25\%), and S. epidermidis (13\%) were the main causes of CoNSassociated UTIs in community and hospital infections in Benin. ${ }^{44}$ It is known that $S$. saprophyticus produces urease, which is essential for colonization and protection in host tissues, by causing tissue damage and invasion and is an important marker of bacterial infections. ${ }^{79,80}$ Specifically, S. saprophyticus subsp. saprophyticus is known for its preference for the rectum and genitourinary tract particularly in young women; this genitourinary adaptation is supported by their increased affinity for hemagglutination and adhesion to uroepithelial cell fibronectin. ${ }^{39,81}$ It is also the second most reported cause of uncomplicated lower UTIs in young females who are sexually active. These factors make the isolation of CoNS especially $S$. saprophyticus, in the genitourinary tract significant. ${ }^{30,39}$ It is therefore important to determine the specific CoNS species to confirm relevance in UTIs. Thus, the lack of species determination in some studies investigating CoNS in UTIs is a shortfall.

\section{Wound infections}

The colonization of burn wounds by microorganisms is a common occurrence especially with major burn wounds. Initially, organisms residing in the skin and throat, such as Staphylococci and Streptococci, may colonize wounds and may be followed later by gastrointestinal bacteria such as E. coli, Proteus, and Klebsiella. ${ }^{82}$ Also, formites and hands of personnel can serve as sources of bacteria in the transmission of infections in burn wounds. These pathogens can 
cause overt wound infection and can lead to bloodstream invasion, leading to delayed wound healing and sepsisrelated mortality. ${ }^{82}$ In a South African study to characterize burn wounds, CoNS were less prevalent (3.2\%) compared with S. aureus (27.7\%), Klebsiella pneumoniae (13.4\%), and Proteus mirabilis $(12.4 \%){ }^{82}$

Conversely, CoNS accounted for a high incidence of surgical site infections, following surgical procedures, when surgical site infections were characterized (Table 1). ${ }^{6}$ Surgical site infections are infections affecting either the incision or deep tissue at the site of operation, and occurs up to 30 days postsurgery or up to 1 year in cases of those with implants. ${ }^{6}$ Although improvements have been made in the prevention of postsurgical infections, surgical site infections remain problematic in surgical practice and account for increased cost of health care and prolonged hospitalization. ${ }^{83}$ Studies show that most of the causes of surgical site infections are normal residents of the skin, such as CoNS and S. aureus. ${ }^{83,84}$ The MR-CoNS detected were $0 \%$ resistant to vancomycin. Increased resistance of CoNS in such instances may be due to increased use of broad-spectrum antibiotics or prolonged hospital stay.

\section{Multiple-source infections}

Blood and CSF were analyzed to investigate severe infections due to invasive bacteria in a Nigerian hospital and detected a CoNS prevalence of $0.5 \%$. CoNS were resistant to cotrimoxazole and erythromycin with a suspected diagnosis of meningitis. ${ }^{85}$ The impact may be underestimated due to lack of diagnostic capacity in resource-constrained countries, as many diseases are not properly investigated.

Azih and Enabulele demonstrated that $34.2 \%$ of the CoNS isolates from various sources demonstrated hemolysis on blood agar, with S. haemolyticus $(58.8 \%)$ and S. epidermidis (25\%) showing the most hemolytic activity. Again, $75.95 \%$ of CoNS samples demonstrated slime production, with all $S$. simulans and $S$. xylosus isolates showing slime production. ${ }^{1} S$. haemolyticus and $S$. saprophyticus were isolated from infection sites with suspected cervicitis and pelvic inflammatory disease. S. epidermidis, S. saprophyticus, and $S$. simulans were implicated in ear, nose, and throat infection in that study. ${ }^{1}$

CoNS were the commonest bacteria isolated in a study conducted to describe the clinical features and microbiological characteristics of febrile illnesses in in-patients being treated for acute lymphoblastic leukemia and acute myeloid leukemia. ${ }^{40}$ Febrile neutropenia and other kinds of infections are common in patients with acute leukemia, leading to decreased survival rates, with studies attributing $60 \%$ of deaths in acute lymphoblastic leukemia patients to complications of infectious diseases. ${ }^{86}$ Delays in initiating antibiotic therapy and hospitalization can be contributing factors to increased mortality.

While investigating the antibiotic susceptibility of CoNS in a Tunisian study, Bouchami et al., as expected, found MR-CoNS to be more resistant to antibiotics compared with methicillin-susceptible CoNS, but the MR-CoNS were susceptible to vancomycin, and displayed only $6 \%$ resistance to teicoplanin. $^{22}$ Methicillin resistance in pathogenic CoNS further complicates antibiotic therapy and restricts treatment options, with some studies reporting oxacillin resistance in
CoNS approaching $90 \% .^{22,87,88}$ The complete susceptibility of isolates in that study to vancomycin is significant as the antibiotic is used in neutropenic patients as empiric therapy. The first case of teicoplanin and vancomycin resistance in CoNS was reported in S. haemolyticus. This species is thus considered particularly inclined to develop glycopeptide resistance among the CoNS group. ${ }^{89}$

Nanoukon et al. found high resistance rates of CoNS to various antibiotics, including penicillin (92\%), fosfomycin $(81 \%)$, cefoxitin $(74 \%)$, and trimethoprim/sulfamethoxazole $(72 \%)$. That most of the virulence determinants such as esterase, enterotoxins, protease, and hemolysins were from blood isolates in that study, may suggest that these CoNS isolates may be adapted to colonize blood. ${ }^{44}$ The most frequently isolated CoNS species in that study were $S$. haemolyticus (44\%), S. epidermidis (22\%), and S. hominis (7\%).

Comparatively, regarding the transmission in health care facilities and their ability to cause outbreaks globally, little is known about CoNS compared with $S$. aureus and many CoNS outbreak cases globally remain unidentified. However, a number of antibiotic-resistant clones of CoNS have been found as causes of outbreaks in Italy ${ }^{90}$ and Brazil. ${ }^{91}$ As well, CoNS have been implicated in BSIs, ${ }^{92} \mathrm{CRBSI},{ }^{93}$ and continuous ambulatory peritoneal dialysis-related infection peritonitis $^{94}$ in Turkey, Germany, and South Korea, respectively at varying levels of prevalence.

\section{Occurrence, Role, and Antibiotic Susceptibility of Suspected Clinically Relevant CoNS in Animals, Within Africa, Since 2009}

Foodborne diseases contribute to significant morbidity and mortality worldwide and cause great economic losses. The sporadic or outbreak cases of foodborne diseases worldwide coupled with the globalization of food supply results in food safety and security concerns. An understanding of the causative pathogen will inform appropriate food safety and public health policies. ${ }^{95}$

CoNS are frequently isolated pathogens in herd milk samples. There has been a shift in mastitis-associated pathogens over the years with hitherto less common pathogens becoming more frequently involved in mastitis pathogenesis. ${ }^{96}$ For instance, Streptococcus agalactiae was the major mastitis pathogen before the use of penicillin G in 1943, but $S$. aureus has since replaced $S$. agalactiae as the major mastitogenic pathogen. ${ }^{96}$

Mastitis is an inflammation of the mammary gland usually caused by microorganisms that colonize the udder. It can result in severe economic losses as a result of decreased milk yield, poor quality of milk, and high cost of treatment in affected cows and affects the dairy industry worldwide. ${ }^{97}$ CoNS are leading etiological agents in mastitis worldwide, however in Africa, little is known about their involvement and antibiotic susceptibility, including methicillin resistance. Bacterial pathogens continue to increase in relevance due to factors such as the development of newer antibiotics, increased milk production, housing systems, and milk-making machines. ${ }^{96}$

Milk samples from dairy herds in South Africa were examined to specifically observe the trends of microorganisms under field conditions. ${ }^{96}$ There was an observed decrease in mastitis over the period considered (1996-2007). The most 
frequently isolated microorganisms from milk samples were CoNS, in both dry $(61.71 \%)$ and lactating cows $(60.96 \%)$ (Table 2). This was followed by S. aureus $(17.28 \%$ for dry and $16.9 \%$ for lactating cows). ${ }^{96}$ Due to its ability to establish chronic infection and its economic impact, $S$. aureus remained the major mastitogenic pathogen in South Africa, but CoNS was found to be the cause of mastitis in majority of cases, underlining the increasing importance of CoNS in livestock. CoNS was responsible for $71.5 \%$ of teat canal infection in quarter milk samples from 1996 to 2007.

Furthermore, pertaining to South Africa, a study found that increase in herd size, poor milking practices, and poor maintenance of milking machines increased udder exposure to pathogens. ${ }^{96}$ CoNS need to be looked at in a new light considering that most mastitis cases in South Africa were caused by CoNS. The study was conducted in seven out of nine provinces in South Africa, thus it reflects the general state of udder health of cattle in the country even though varying factors such as management skills, milking frequency, milk yield and herd size may limit the generalization of results. Despite the development and improvement in animal husbandry practices, bovine mastitis remains a cause for economic concern due to the economic losses the disease carries. ${ }^{96}$ It is thus important to be acquainted with possible mastitogenic pathogens, and their epidemiology, trends in disease causation to help in effective infection control and policy regulations.

A similar CoNS prevelance rate of $66.3 \%$ was observed in another South African study, which aimed to determine the distribution of mastitogenic pathogens. ${ }^{98}$

In another study, multidrug resistance was observed in $37.3 \%$ of isolates, among the CoNS of bovine origin, whereas $89.5 \%$ of CoNS from close human contacts were multidrug resistant (Table 2). ${ }^{26}$ The high level of multidrug resistance in human CoNS suggests humans could be reservoirs for resistance genes. In bovine CoNS, complete susceptibility was observed toward cefoxitin, cephalothin, moxifloxacin, clindamycin, erythromycin, gentamicin, and linezolid, whereas the highest resistance values were observed against penicillin $(37.3 \%)$ and ampicillin $(36.3 \%)$. These two $\beta$-lactam antibiotics are commonly used in the prophylaxis and treatment of IMIs in dairy cows, being found in more than half of preparations used for such purpose in South Africa. The different susceptibility patterns observed across the continent may be explained by different antibiotic usage as well as difference in implementation of antibiotic regulation. Pathogenic CoNS causes of IMIs may be herd specific and linked to certain management practices. S. chromogenes has been found to be specifically adjusted to udder, making it a persistent cause of IMIs. ${ }^{99}$

MR-CoNS were prevalent in $57 \%$ of cows in a study, which also recorded vancomycin-resistant CoNS ( $S$. hominis and S. lugdunensis). ${ }^{97}$ Even though similar species were seen from both bovine and human samples, different genotyping characteristics suggests there was no zoonotic transfer. All staphylococcal isolates from cows were sensitive to daptomycin, ciprofloxacin, gentamicin, linezolid, mupirocin, and moxifloxacin.

Conversely, in an Uganda study, all cattle staphylococcal isolates showed $100 \%$ resistance to penicillin $G$ and ampicillin and were $\beta$-lactamase producers, with $\beta$-lactamase production also being observed in $80 \%$ of CoNS isolates. ${ }^{100}$ Intramammary infusions of either tetracycline or ampicillin were commonly used in mastitis cases, and this could partly be responsible for resistance observed against tetracycline (33\%). Improved milking practices such as use of milking machines instead of hand milking and improved udder hygiene are important. Control of mastitis requires effective husbandry practices. The heavy use of antibiotics in livestock production for treatment and as prophylaxis, has been in part, blamed for contributing to antimicrobial resistance.

Klibi et al. while characterizing MR-CoNS and methicillinsusceptible coagulase-negative staphylococci (MSCoNS) from cows with clinical mastitis, found that $70 \%$ of MR-CoNS carried the mecA gene, but all MR-CoNS isolates lacked the mec $C$ gene; however, the resistance genes $\operatorname{tet}(\mathrm{K}), \operatorname{dfr}(\mathrm{A})$, $\operatorname{Inu}(\mathrm{B}), \operatorname{erm}(\mathrm{C}), \operatorname{erm}(\mathrm{B}), \operatorname{erm}(\mathrm{T}), \operatorname{mph}(\mathrm{C})$, or $\operatorname{msr}(\mathrm{A})$ were detected. ${ }^{41}$ The phenotypic observance of methicillin resistance without the genotypic detection of $m e c A$ or other known methicillin resistance mechanisms may be due to the emergence of a new methicillinase, overproduction of $\beta$-lactamases, or the changes in binding affinity of penicillin-binding proteins. $^{101,102}$ It is thus important to investigate alternative methicillin resistance mechanisms.

The variety of ARGs in CoNS in milk of mastitis cows could lead to horizontal transfer to other staphylococcal species, some of which are more virulent, leading to food safety concerns. Methicillin-resistant $S$. epidermidis for example may play the role of reservoirs of ARGs which can be transferred. This occurrence is more of a concern considering S. epidermidis is a suspected zoonotic pathogen. In comparison to MR-CoNS, the MS-CoNS isolates showed lower levels of resistance to antibiotics. ${ }^{41}$ This was expected, as methicillin resistance is known to cause cross resistance to other antibiotics. ${ }^{103}$ Dhaouadi et al. however, reported the first occurrence of mecC gene in CoNS ( $S$. sciuri) in Africa (having been already reported in animals in Europe), ${ }^{104}$ obtained from cows and manure, in a study which also found the ARGs tet $(\mathrm{K})$, mecA, $\operatorname{msr}(\mathrm{A}), \operatorname{blaZ}, \operatorname{erm}(\mathrm{A})$, and $\operatorname{erm}(\mathrm{B})$ simultaneously from cow (milk), manure, and human (nares) sources, which may be suggestive of an exchange of ARGs among these sources. ${ }^{105}$ In the study by Dhaouadi et al., mecA was predominantly found in $S$. sciuri, which was also the only species to possess the $m e c \mathrm{C}$ gene, stressing its importance as reservoir. Furthermore, the possession of mec A and mec C by S. sciuri in cow milk and manure represents a threat of transfer to humans, especially as $S$. sciuri has been reported as a cause of severe human infection. ${ }^{106}$ Other CoNS prevalence studies in mastitis have found $27.6 \%,{ }^{107} 40.2 \%,{ }^{108}$ and $10.5 \%{ }^{109}$ in Zimbabwe, Rwanda, and Ethiopia, respectively, as causes of mastitis.

In comparison to the global situation, the increasing importance of CoNS in IMIs is evinced by their high occurrence in countries such as Belgium, ${ }^{110}$ Germany $(9.1 \%),{ }^{111}$ Sweden $(16 \%){ }^{112}$ and the United States $(15 \%){ }^{113}$

\section{Typing methods for CoNS}

Clonal diversity/relatedness studies in CoNS have not been given much attention as compared with $S$. aureus. Pulsed-field gel electrophoresis (PFGE) has shown that CoNS species, such as $S$. lugdunensis, $S$. haemolyticus, and $S$. schleiferi are not as clonally diverse as $S$. aureus, which is characterized by a wide genomic diversity. ${ }^{114,115}$ SCCmec typing is important for characterizing MR-CoNS clones in epidemiological studies.

While investigating the characterization of methicillinresistant and susceptible CoNS obtained from cow milk 
samples, Klibi et al., using SCCmec typing, discovered methicillin-resistant $S$. epidermidis possessed $S C C$ mec typeIva. ${ }^{41}$ The isolates also possessed the recombinase genes $\mathrm{ccr}$ A2/B2-class B mec gene complex determined by PCR of the ccr recombinases (1-5). Also, Ehlers et al. found that $S C C$ mec type IV was the most predominant with $31 \%$ of $S$. epidermidis isolates belonging to that class. The same study using MLST, grouped isolates mainly into the groups; sequence type (ST) 2 as the most predominant, followed by ST54, ST59, and ST490 in descending order of predominance, with one isolate being assigned to a new group, ST596. ${ }^{75}$

SCCmec types I, II, IV, and V/VII have also been reported in a Tunisian study, which also found diverse PFGE patterns within mecA-positive CoNS isolates. The observation of similar SCCmec and PFGE patterns of MR-CoNS across different sources in that study means there was the transfer and circulation of the same clones at the human/animal/environment interface. $^{105}$

That genetic typing of CoNS has not been given attention as $S$. aureus and other pathogens is shown by the fact only a few studies performed genetic typing even when CoNS were the major pathogens suspected of causing infection. Thus, it is difficult to ascertain the most common clones or types circulating on the continent. The aforementioned methods together have served microbiologists well, however, they are limited in their ability to discriminate bacterial strains that originated from a single bacterial clone. ${ }^{116}$ Thus, WGS is an ideal epidemiological typing tool due to its ability to detect single changes in the genomes between two isolates and can identify new types or subtypes. ${ }^{34}$ Effective epidemiological typing can assist in, for example linking hospital-endemic clones of CoNS to possession of resistance and virulence determinants. $^{42}$ Although high-throughput sequencing techniques are relatively cheaper now, in resource-constrained settings, such as in most parts of Africa, it has yet to be a frequent tool employed in routine epidemiological studies.

\section{Treatment of CoNS infections}

Treatment options for CoNS are limited because many of them are methicillin resistant. Thus, the glycopeptides (particularly vancomycin) are relied upon, especially in infections caused by the $S$. epidermidis group. ${ }^{30}$ For isolates that are sensitive to methicillin, penicillin, and first- or secondgeneration cephalosporins may be used. On the other hand, cotrimoxazole or newer generation antibiotics such as linezolid, daptomycin may be administered, where methicillin resistance is observed. ${ }^{30}$ Infections associated with invasive devices should have tailored treatment regimens, considering the role of the devices. These include catheter-associated UTIs. In these cases, removal of devices may be considered, and comes with additional medical procedures with associated extra costs. In some instances, removal of device can be enough to curtail infection. If devices are retained, antimicrobial therapy should be given $10-14$ days. ${ }^{30}$ Susceptibility patterns of CoNS should be considered to inform both empiric and specific treatment.

\section{Methods \& Results Obtained}

\section{Literature search}

PubMed, Google Scholar, Science Direct and Web of Science were searched for English research articles, using the following combined search term: "(Coagulase-negative staphylococcus*) AND (Africa OR West Africa OR East Africa OR Southern Africa OR North Africa OR Central Africa)".

\section{Study selection}

Articles published in 2009 or later (from 2009 to 2019), describing clinically relevant CoNS, including patterns, frequency, epidemiology, diagnoses, and treatment in Africa were included. Non-English articles were excluded. Only research articles, wherein CoNS were suspected to have caused infections in both humans and animals, were included. All articles that did not discuss CoNS, those not conducted in Africa and those published before 2009 were excluded. All abstracts, reviews, and conference proceedings or articles were not included. The search yielded $>1,700$ items. Of these, 35 articles were included based on the inclusion criteria described above.

\section{Limitations, future perspective, and conclusions}

The increasing availability of next-generation sequencing tools due to their decreasing costs has yet to be reflected in Africa, by their scarce use in routine investigations, at least in large microbiology laboratories. The acquisition of bench-top high-throughput sequencing devices will be important to investigate outbreaks of CoNS infections at reduced turnaround times. This will lead to a thorough assessment of the true infectious/virulent potential of isolated CoNS species and inform prompt clinical decisions.

CoNS are becoming increasingly relevant, clinically and epidemiologically, as seen in the number of infections, morbidity, and mortality attributed to them. Although they are mostly classified as mere contaminants, they may be the true causes of infections in certain cases. There is a marked species diversity of CoNS across the continent of Africa, and there is the need for increased laboratory capacity for effective speciation of CoNS at reduced costs. The deployment of molecular and spectrometric techniques for detection where affordable are needed to complement basic biochemical methods for effective diagnoses.

Care should be taken in patients harboring invasive devices, while decreasing the risk for contamination during insertion and sample taking. The lack of epidemiological typing of CoNS, lack of virulence screening, and the lack of assessment of the immune status of subjects in many studies considered, limit the assessment of the true pathogenic potential of CoNS species in Africa. Further studies investigating the role of CoNS, including thorough characterization of recovered need, are to be carried out in Africa.

\section{Disclosure Statement}

S.Y.E. is the chairperson of the Global Respiratory Infection Partnership sponsored by an unrestricted educational grant from Reckitt and Benckiser (Pty.) UK. For all other authors, no competing financial interests exist.

\section{Funding Information}

This research received no external funding.

\section{References}

1. Azih, A., and I. Enabulele. 2013. Species distribution and virulence factors of coagulase negative Staphylococci 
isolated from clinical samples from the University of Benin Teaching hospital, Edo State, Nigeria. J. Nat. Sci. Res. 3:38-43.

2. Cunha, M.d.L.R.d., L.M.S.d.S. Rugolo, and C.a.d.M. Lopes. 2006. Study of virulence factors in coagulasenegative staphylococci isolated from newborns. Mem. Inst. Oswaldo Cruz. 101:661-668.

3. Ogbolu, D., O. Alli, I. Ephraim, F. Olabiyi, and O. Daini. 2011. In-Vitro efficacy of antimicrobial agents used in the treatment of bacterial eye infections in Ibadan, Nigeria. Afr. J. Clin. Exper. Microbiol. 12:124-127.

4. Trampuz, A., and W. Zimmerli. 2005. Prosthetic joint infections: update in diagnosis and treatment. Swiss Med. Wkly. 135:243-251.

5. Longauerova, A. 2006. Coagulase negative staphylococci and their participation in pathogenesis of human infections. Bratisl. Lek. Listy. 107:448.

6. Iyamba, J.-M.L., J.M. Wambale, and C.M. Lukukula. 2014. High prevalence of methicillin resistant staphylococci strains isolated from surgical site infections in Kinshasa. Pan Afr. Med. J. 18:322.

7. Patel, R., K.E. Piper, M.S. Rouse, J.R. Uhl, F.R. Cockerill, and J.M. Steckelberg. 2000. Frequency of isolation of Staphylococcus lugdunensisamong Staphylococcal isolates causing endocarditis: a 20 -year experience. J. Clin. Microbiol. 38:4262-4263.

8. Vanderhaeghen, W., S. Piepers, F. Leroy, E. Van Coillie, F. Haesebrouck, and S. De Vliegher. 2014. Invited review: effect, persistence, and virulence of coagulase-negative Staphylococcus species associated with ruminant udder health. J. Dairy Sci. 97:5275-5293.

9. Ikem, I., L. Oginni, E. Bamgboye, A. Ako-Nai, and A. Onipede. 2004. The bacteriology of open fractures in IleIfe, Nigeria. Niger. J. Med. 13:359-365.

10. Vogel, L., J.H. Sloos, J. Spaargaren, I. Suiker, and L. Dijkshoorn. 2000. Biofilm production by Staphylococcus epidermidis isolates associated with catheter related bacteremia. Diagn. Microbiol. Infect. Dis. 36:139-141.

11. Piette, A., and G. Verschraegen. 2009. Role of coagulasenegative staphylococci in human disease. Vet. Microbiol. 134:45-54.

12. Mbanga, J., S. Masuku, and S. Luphahla. 2016. Antibiotic resistance patterns and virulence factors of coagulase negative staphylococcus associated with urinary tract infections in Bulawayo Province, Zimbabwe. Br. J. Med. Med. Res. 2016:1-9.

13. Bassetti, M., E.M. Trecarichi, A. Mesini, T. Spanu, D. Giacobbe, M. Rossi, E. Shenone, G. Pascale, M. Molinari, and R. Cauda. 2012. Risk factors and mortality of healthcare-associated and community-acquired Staphylococcus aureus bacteraemia. Clin. Microbiol. Infect. 18: 862-869.

14. Shittu, A., O. Oyedara, F. Abegunrin, K. Okon, A. Raji, S. Taiwo, F. Ogunsola, K. Onyedibe, and G. Elisha. 2012. Characterization of methicillin-susceptible and -resistant staphylococci in the clinical setting: a multicentre study in Nigeria. BMC Infect. Dis. 12:286.

15. Bourgeois, I., M. Pestel-Caron, J.-F. Lemeland, J.-L. Pons, and F. Caron. 2007. Tolerance to the glycopeptides vancomycin and teicoplanin in coagulase-negative staphylococci. Antimicrob. Agents Chemother. 51:740-743.

16. Ma, X.X., E.H. Wang, Y. Liu, and E.J. Luo. 2011. Antibiotic susceptibility of coagulase-negative staphylococci (CoNS): emergence of teicoplanin-non-susceptible CoNS strains with inducible resistance to vancomycin. J. Med. Microbiol. 60:1661-1668.

17. May, L., E.Y. Klein, R.E. Rothman, and R. Laxminarayan. 2014. Trends in antibiotic resistance in coagulase-negative staphylococci in the United States, 1999 to 2012. Antimicrob. Agents Chemother. 58:1404-1409.

18. Natoli, S., C. Fontana, M. Favaro, A. Bergamini, G.P. Testore, S. Minelli, M.C. Bossa, M. Casapulla, G. Broglio, and A. Beltrame. 2009. Characterization of coagulasenegative staphylococcal isolates from blood with reduced susceptibility to glycopeptides and therapeutic options. BMC Infect. Dis. 9:83.

19. Iweriebor, B., N. Ramalivhana, T. Hattori, A. Okoh, and C. Obi. 2013. Vancomycin resistant coagulase-negative Staphylococcal isolates from HIV positive patients in the Limpopo Province, South Africa. J. Microbiol. Antimicrob. 5:18-24.

20. Agvald-Öhman, C., B. Lund, and C. Edlund. 2003. Multiresistant coagulase-negative staphylococci disseminate frequently between intubated patients in a multidisciplinary intensive care unit. Critical Care. 8:R42.

21. Diekema, D., M. Pfaller, F. Schmitz, J. Smayevsky, J. Bell, R. Jones, M. Beach, and SENTRY Partcipants Group. 2001. Survey of infections due to Staphylococcus species: frequency of occurrence and antimicrobial susceptibility of isolates collected in the United States, Canada, Latin America, Europe, and the Western Pacific region for the SENTRY Antimicrobial Surveillance Program, 1997-1999. Clin. Infect. Dis. 32(Suppl2):S114-S132.

22. Bouchami, O., W. Achour, and A.B. Hassen. 2011. Species distribution and antibiotic sensitivity pattern of coagulase-negative Staphylococci other than Staphylococcus epidermidis isolated from various clinical specimens. Afr. J. Microbiol. Res. 5:1298-1305.

23. Parte, A.C. 2018. LPSN-list of prokaryotic names with standing in nomenclature (bacterio. net), 20 years on. Int. J. Syst. Evol. Microbiol. 68:1825-1829.

24. Heilmann, C., W. Ziebuhr, and K. Becker. 2019. Are coagulase-negative staphylococci virulent? Clin. Microbiol. Infect. 5:1071-1080.

25. Zadoks, R.N., J.R. Middleton, S. McDougall, J. Katholm, and Y.H. Schukken. 2011. Molecular epidemiology of mastitis pathogens of dairy cattle and comparative relevance to humans. J. Mammary Gland Biol. Neoplasia. 16: 357-372.

26. Schmidt, T., M.M. Kock, and M.M. Ehlers. 2015. Diversity and antimicrobial susceptibility profiling of staphylococci isolated from bovine mastitis cases and close human contacts. J. Dairy Sci. 98:6256-6269.

27. Vanderhaeghen, W., S. Piepers, F. Leroy, E. Van Coillie, F. Haesebrouck, and S. De Vliegher. 2015. Identification, typing, ecology and epidemiology of coagulase negative staphylococci associated with ruminants. Vet. J. 203:44-51.

28. García, P., R. Benítez, M. Lam, A.M. Salinas, H. Wirth, C. Espinoza, T. Garay, M.S. Depix, J. Labarca, and A.M. Guzmán. 2004. Coagulase-negative staphylococci: clinical, microbiological and molecular features to predict true bacteraemia. J. Med. Microbiol. 53:67-72.

29. Becker, K., R. Skov, C. von Eiff. 2015. Staphylococcus, Micrococcus, and Other Catalase-Positive Cocci. In J. Jorgensen, M. Pfaller, K. Carroll, G. Funke, M. Landry, S. Richter, D. Warnock (ed.), Manual of Clinical Microbiology, Eleventh Edition. ASM Press, Washington, DC, pp. 354-382. 
30. Becker, K., C. Heilmann, and G. Peters. 2014. Coagulasenegative staphylococci. Clin. Microbiol. Rev. 27:870-926.

31. Bizzini, A., K. Jaton, D. Romo, J. Bille, G. Prod'hom, and G. Greub. 2011. Matrix-assisted laser desorption ionization-time of flight mass spectrometry as an alternative to 16S rRNA gene sequencing for identification of difficult-toidentify bacterial strains. J. Clin. Microbiol. 49:693-696.

32. Schmidt, T., M.M. Kock, and M.M. Ehlers. 2018. Identification and characterization of Staphylococcus devriesei isolates from bovine intramammary infections in KwaZuluNatal, South Africa. BMC Vet. Res. 14:324.

33. Lamers, R.P., G. Muthukrishnan, T.A. Castoe, S. Tafur, A.M. Cole, and C.L. Parkinson. 2012. Phylogenetic relationships among Staphylococcus species and refinement of cluster groups based on multilocus data. BMC Evol. Biol. 12:171.

34. Bertelli, C., and G. Greub. 2013. Rapid bacterial genome sequencing: methods and applications in clinical microbiology. Clin. Microbiol. Infect. 19:803-813.

35. Osei Sekyere, J., and J. Asante. 2018. Emerging mechanisms of antimicrobial resistance in bacteria and fungi: advances in the era of genomics. Future Microbiol. 13:241-262.

36. Osei Sekyere, J., U. Govinden, and S. Essack. 2015. Review of established and innovative detection methods for carbapenemase-producing Gram-negative bacteria. J. Appl. Microbiol. 119:1219-1233.

37. Grice, E.A., and J.A. Segre. 2011. The skin microbiome. Nat. Rev. Microbiol. 9:244.

38. Grice, E.A., H.H. Kong, S. Conlan, C.B. Deming, J. Davis, A.C. Young, G.G. Bouffard, R.W. Blakesley, P.R. Murray, and E.D. Green. 2009. Topographical and temporal diversity of the human skin microbiome. Science. 324:1190-1192.

39. Fontana, C., M. Favaro. 2018. Coagulase-positive and coagulase-negative staphylococci in human disease. In V. Savino (ed.), Pet-to-Man Travelling Staphylococci. Academic Press, London, UK, pp. 25-42.

40. DePasse, J., M.A. Caniza, A. Quessar, M. Khattab, L. Hessissen, R. Ribeiro, S. Cherkaoui, S. Benchekroun, and K.K. Matthay. 2013. Infections in hospitalized children and young adults with acute leukemia in Morocco. Pediatr. Blood Cancer. 60:916-922.

41. Klibi, A., A. Maaroufi, C. Torres, and A. Jouini. 2018. Detection and characterization of methicillin-resistant and susceptible coagulase-negative staphylococci in milk from cows with clinical mastitis in Tunisia. Int. J. Antimicrob. Agents. 52:930-935.

42. Klingenberg, C., A. Rønnestad, A. Anderson, T. Abrahamsen, J. Zorman, A. Villaruz, T. Flaegstad, M. Otto, and J.E. Sollid. 2007. Persistent strains of coagulasenegative staphylococci in a neonatal intensive care unit: virulence factors and invasiveness. Clin. Microbiol. Infect. 13:1100-1111.

43. Qin, L., F. Da, E.L. Fisher, D.C. Tan, T.H. Nguyen, C.-L. Fu, V.Y. Tan, J.W. McCausland, D.E. Sturdevant, and H.-S. Joo. 2017. Toxin mediates sepsis caused by methicillinresistant Staphylococcus epidermidis. PLoS Pathog. 13: e1006153.

44. Nanoukon, C., X. Argemi, F. Sogbo, J. Orekan, D. Keller, D. Affolabi, F. Schramm, P. Riegel, L. Baba-Moussa, and G. Prévost. 2017. Pathogenic features of clinically significant coagulase-negative staphylococci in hospital and community infections in Benin. Int. J. Med. Microbiol. 307:75-82.
45. Otto, M. 2004. Virulence factors of the coagulasenegative staphylococci. Front Biosci. 9:841-863.

46. Mvalo, T., B. Eley, C. Bamford, C. Stanley, M. Chagomerana, M. Hendricks, A. Van Eyssen, and A. Davidson. 2018. Bloodstream infections in oncology patients at Red Cross War Memorial Children's Hospital, Cape Town, from 2012 to 2014. Int. J. Infect. Dis. 77:40-47.

47. Ballot, D.E., T. Nana, C. Sriruttan, and P.A. Cooper. 2012. Bacterial bloodstream infections in neonates in a developing country. ISRN pediatrics. 2012:508512.

48. Morkel, G., A. Bekker, B. Marais, G.V. Kirsten, J. Van Wyk, and A. Dramowski. 2014. Bloodstream infections and antimicrobial resistance patterns in a South African neonatal intensive care unit. Paediatr. Int. Child Health. 34:108-114.

49. Mashaly, G.E.-S., and R.H. El-Mahdy. 2017. Vancomycin heteroresistance in coagulase negative Staphylococcus blood stream infections from patients of intensive care units in Mansoura University Hospitals, Egypt. Ann. Clin. Microbiol. Antimicrob. 16:63.

50. Adeyemi, A.I., A.A. Sulaiman, B.B. Solomon, O.A. Chinedu, and I.A. Victor. 2010. Bacterial bloodstream infections in HIV-infected adults attending a Lagos teaching hospital. J. Health Popul. Nutr. 28:318.

51. Rogers, K.L., P.D. Fey, and M.E. Rupp. 2009. Coagulasenegative staphylococcal infections. Infect. Dis. Clin. North Am. 23:73-98.

52. Schommer, N.N., M. Christner, M. Hentschke, K. Ruckdeschel, M. Aepfelbacher, H. Rohde. 2011. Staphylococcus epidermidis uses distinct mechanisms of biofilm formation to interfere with phagocytosis and activation of mouse macrophage-like cells 774A. 1. Infect. Immun. 79: 2267-2276.

53. Izano, E.A., M.A. Amarante, W.B. Kher, and J.B. Kaplan. 2008. Differential roles of poly-N-acetylglucosamine surface polysaccharide and extracellular DNA in Staphylococcus aureus and Staphylococcus epidermidis biofilms. Appl. Environ. Microbiol. 74:470-476.

54. Yu, W., H.K. Kim, S. Rauch, O. Schneewind, and D. Missiakas. 2017. Pathogenic conversion of coagulasenegative staphylococci. Microb. Infect. 19:101-109.

55. Dimitriou, G., S. Fouzas, N. Giormezis, I. Giannakopoulos, S. Tzifas, A. Foka, D. Anastassiou, I. Spiliopoulou, and S. Mantagos. 2011. Clinical and microbiological profile of persistent coagulase-negative staphylococcal bacteraemia in neonates. Clin. Microbiol. Infect. 17:1684-1690.

56. Lepainteur, M., G. Royer, A. Bourrel, O. Romain, C. Duport, F. Doucet-Populaire, J.-W. Decousser. 2013. Prevalence of resistance to antiseptics and mupirocin among invasive coagulase-negative staphylococci from very preterm neonates in NICU: the creeping threat? J. Hosp. Infect. 83:333-336.

57. Patel, S.J., and L. Saiman. 2010. Antibiotic resistance in neonatal intensive care unit pathogens: mechanisms, clinical impact, and prevention including antibiotic stewardship. Clin. Perinatol. 37:547-563.

58. Van der Zwet, W., A. Kaiser, R. Van Elburg, J. Berkhof, W. Fetter, G. Parlevliet, and C. Vandenbroucke-Grauls. 2005. Nosocomial infections in a Dutch neonatal intensive care unit: surveillance study with definitions for infection specifically adapted for neonates. J. Hosp. Infect. 61:300311.

59. Couto, R.C., E.A. Carvalho, T.M. Pedrosa, E.R. Pedroso, M.C. Neto, and F.M. Biscione. 2007. A 10-year prospective 
surveillance of nosocomial infections in neonatal intensive care units. Am. J. Infect. Control. 35:183-189.

60. Zaidi, A.K., W.C. Huskins, D. Thaver, Z.A. Bhutta, Z. Abbas, and D.A. Goldmann. 2005. Hospital-acquired neonatal infections in developing countries. Lancet. 365: $1175-1188$.

61. Kayange, N., E. Kamugisha, D.L. Mwizamholya, S. Jeremiah, and S.E. Mshana. 2010. Predictors of positive blood culture and deaths among neonates with suspected neonatal sepsis in a tertiary hospital, Mwanza-Tanzania. BMC Pediatr. 10:39.

62. Kabwe, M., J. Tembo, L. Chilukutu, M. Chilufya, F. Ngulube, C. Lukwesa, M. Kapasa, V. Enne, H. Wexner, and L. Mwananyanda. 2016. Etiology, antibiotic resistance and risk factors for neonatal sepsis in a large referral center in Zambia. Pediat. Infect. Dis. J. 35:e191-e8.

63. Ogunlesi, T.A., O.B. Ogunfowora, O. Osinupebi, and D.M. Olanrewaju. 2011. Changing trends in newborn sepsis in Sagamu, Nigeria: bacterial aetiology, risk factors and antibiotic susceptibility. J. Paediatr. Child Health. 47: $5-11$.

64. Adeyemo, W.L., M.O. Adeyemi, F.T. Ogunsola, M.O. Ogunlewe, A.L. Ladeinde, B.O. Mofikoya, and A. Butali. 2013. Prevalence and bacteriology of bacteremia associated with cleft lip and palate surgery. J. Craniofac. Surg. 24:1126-1131.

65. Choi, G., M.P. van den Borne, C.E. Visser, M.J. Kersten, and A.P. Kater. 2008. Invasive infections with a coagulasenegative staphylococcus in an immunocompromised patient: case report and review of the literature. Ann. Hematol. 87:771-772.

66. Stoll, B.J., N. Hansen, A.A. Fanaroff, L.L. Wright, W.A. Carlo, R.A. Ehrenkranz, J.A. Lemons, E.F. Donovan, A.R. Stark, and J.E. Tyson. 2002. Late-onset sepsis in very low birth weight neonates: the experience of the NICHD Neonatal Research Network. Pediatrics. 110: 285-291.

67. Venkatesh, M.P., F. Placencia, and L.E. Weisman. 2006. Coagulase-negative staphylococcal infections in the neonate and child: an update. Semin. Pediatr. Infect. Dis. 17: $120-127$.

68. Seale, A.C., C.W. Obiero, K.D. Jones, H.C. Barsosio, J. Thitiri, M. Ngari, S. Morpeth, S. Mohammed, G. Fegan, and N. Mturi. 2017. Should first-line empiric treatment strategies for neonates cover coagulase-negative staphylococcal infections in Kenya? Pediatr. Infect. Dis. J. 36: 1073.

69. Acquah, S.E., L. Quaye, K. Sagoe, J.B. Ziem, P.I. Bromberger, and A.A. Amponsem. 2013. Susceptibility of bacterial etiological agents to commonly-used antimicrobial agents in children with sepsis at the Tamale Teaching Hospital. BMC Infect. Dis. 13:89.

70. Dagnew, M., G. Yismaw, M. Gizachew, A. Gadisa, T. Abebe, T. Tadesse, A. Alemu, and B. Mathewos. 2013. Bacterial profile and antimicrobial susceptibility pattern in septicemia suspected patients attending Gondar University Hospital, Northwest Ethiopia. BMC Res. Notes 6: 283.

71. Moyo, M., S. Aboud, M. Kasubi, and S. Maselle. 2010. Bacteria isolated from bloodstream infections at a tertiary hospital in Dar es Salaam, Tanzania - antimicrobial resistance of isolates. S. Afr. Med. J. 100:835-838.

72. Uche, E., E. Onyia, U. Mezue, E. Okorie, I. Ozor, and M. Chikani. 2013. Determinants and outcomes of ven- triculoperitoneal shunt infections in Enugu, Nigeria. Pediatr. Neurosurg. 49:75-80.

73. Mwang'Ombe, N., and T. Omulo. 2000. Ventriculoperitoneal shunt surgery and shunt infections in children with non-tumour hydrocephalus at the Kenyatta National Hospital, Nairobi. East Afr. Med. J. 77:386-390.

74. Sacar, S., H. Turgut, S. Toprak, B. Cirak, E. Coskun, O. Yilmaz, and K. Tekin. 2006. A retrospective study of central nervous system shunt infections diagnosed in a university hospital during a 4-year period. BMC Infect. Dis. 6:43.

75. Ehlers, M.M., W. Strasheim, M. Lowe, V. Ueckermann, and M.M. Kock. 2018. Molecular epidemiology of Staphylococcus epidermidis implicated in catheter-related bloodstream infections at an Academic Hospital in Pretoria, South Africa. Front. Microbiol. 9:417.

76. Tadesse, E., M. Teshome, Y. Merid, B. Kibret, and T. Shimelis. 2014. Asymptomatic urinary tract infection among pregnant women attending the antenatal clinic of Hawassa Referral Hospital, Southern Ethiopia. BMC Res. Notes. 7:155.

77. Assefa, A., D. Asrat, Y. Woldeamanuel, A. Abdella, and T. Melesse. 2008. Bacterial profile and drug susceptibility pattern of urinary tract infection in pregnant women at Tikur Anbessa Specialized Hospital Addis Ababa, Ethiopia. Ethiop J. Med. 46:227-235.

78. Khan, A.U., and M.S. Zaman. 2006. Multiple drug resistance pattern in urinary tract infection patients in Aligarh. Biomed Res. 17:179-181.

79. Hovelius, B., and P.-A. Mårdh. 1984. Staphylococcus saprophyticus as a common cause of urinary tract infections. Rev. Infect. Dis. 6:328-337.

80. Konieczna, I., P. Zarnowiec, M. Kwinkowski, B. Kolesinska, J. Fraczyk, Z. Kaminski, and W. Kaca. 2012. Bacterial urease and its role in long-lasting human diseases. Curr. Protein Pept. Sci. 13:789-806.

81. Rupp, M.E., D.E. Soper, and G.L. Archer. 1992. Colonization of the female genital tract with Staphylococcus saprophyticus. J. Clin. Microbiol. 30:2975-2979.

82. Bhat, V., and S. Vasaikar. 2010. Bacteriological profile and antibiogram of aerobic burn wound isolates in Mthatha, Eastern Cape, South Africa. South. Afr. J. Epidemiol. Infect. 25:16-19.

83. Owens, C., and K. Stoessel. 2008. Surgical site infections: epidemiology, microbiology and prevention. J. Hosp. Infect. 70:3-10.

84. Dohmen, P. 2008. Antibiotic resistance in common pathogens reinforces the need to minimise surgical site infections. J. Hosp. Infect. 70:15-20.

85. Onipede, A.O., A.A. Onayade, J.B. Elusiyan, P.O. Obiajunwa, E.O. Ogundare, O.O. Olaniran, L.A. Adeyemi, and O.O. Oyelami. 2009. Invasive bacteria isolates from children with severe infections in a Nigerian hospital. J. Infect. Develop. Ctries. 3:429-436.

86. Kulkarni, K., R. Marwaha, A. Trehan, and D. Bansal. 2009. Survival outcome in childhood ALL: experience from a tertiary care centre in North India. Pediatr. Blood Cancer. 53:168-173.

87. John, J.F., and A.M. Harvin. 2007. History and evolution of antibiotic resistance in coagulase-negative staphylococci: susceptibility profiles of new anti-staphylococcal agents. Ther. Clin. Risk Manag. 3:1143.

88. Martins, A., R.S. de Lourdes, and M. Cunha. 2007. Methicillin resistance in Staphylococcus aureus and 
coagulase-negative staphylococci: epidemiological and molecular aspects. Microbiol. Immunol. 51:787-795.

89. Schwalbe, R.S., J.T. Stapleton, and P.H. Gilligan. 1987. Emergence of vancomycin resistance in coagulasenegative staphylococci. N. Engl. J. Med. 316:927-931.

90. Mazzariol, A., G.L. Cascio, E. Kocsis, L. Maccacaro, R. Fontana, and G. Cornaglia. 2012. Outbreak of linezolidresistant Staphylococcus haemolyticus in an Italian intensive care unit. Eur. J. Clin. Microbiol. Infect. Dis. 31: 523-527.

91. de Brito, D.V., E.J. von Dolinger, V.O. Abdallah, A.L.C. Darini, and P.P. Gontijo Filho. 2009. Two outbreaks of mixed etiology associated with central venous catheters inserted by phlebotomy in critical neonates. Br. J. Infect. Dis. 13:177-182.

92. Koksal, F., H. Yasar, and M. Samasti. 2009. Antibiotic resistance patterns of coagulase-negative staphylococcus strains isolated from blood cultures of septicemic patients in Turkey. Microbiol. Res. 164:404-410.

93. Gatermann, S., T. Koschinski, and S. Friedrich. 2007. Distribution and expression of macrolide resistance genes in coagulase-negative staphylococci. Clin. Microbiol. Infect. 13:777-781.

94. Shin, J.H., S.H. Kim, H.S. Jeong, S.H. Oh, H.R. Kim, J.N. Lee, Y.C. Yoon, Y.W. Kim, and Y.H. Kim. 2011. Identification of coagulase-negative staphylococci isolated from continuous ambulatory peritoneal dialysis fluid using 16S ribosomal RNA, tuf, and SodA gene sequencing. Perit. Dial. Int. 31:340-346.

95. Kirk, M.D., S.M. Pires, R.E. Black, M. Caipo, J.A. Crump, B. Devleesschauwer, D. Döpfer, A. Fazil, C.L. Fischer-Walker, and T. Hald. 2015. World Health Organization estimates of the global and regional disease burden of 22 foodborne bacterial, protozoal, and viral diseases, 2010: a data synthesis. PLoS Med. 12: e1001921.

96. Petzer, I.-M., J. Karzis, J.C. Watermeyer, T.J. Van der Schans, and R. Van Reenen. 2009. Trends in udder health and emerging mastitogenic pathogens in South African dairy herds. J. S. Afr. Vet. Assoc. 80:17-22.

97. Kateete, D.P., U. Kabugo, H. Baluku, L. Nyakarahuka, S. Kyobe, M. Okee, C.F. Najjuka, and M.L. Joloba. 2013. Prevalence and antimicrobial susceptibility patterns of bacteria from milkmen and cows with clinical mastitis in and around Kampala, Uganda. PLoS One. 8: e63413.

98. Pekana, A., U.U. Nwodo, A.I. Okoh, and E. Green. 2017. Distribution and antibiotic susceptibility profiles of Staphylococcus spp isolated from unpasteurized cow milk locally consumed in Nkonkobe local municipality, South Africa. Int. J. Appl. Res. Vet. Med. 15:50-59.

99. Supré, K., F. Haesebrouck, R. Zadoks, M. Vaneechoutte, S. Piepers, and S. De Vliegher. 2011. Some coagulasenegative Staphylococcus species affect udder health more than others. J. Dairy. Sci. 94:2329-2340.

100. Björk, S., R. Båge, B.M. Kanyima, S. André, M.G. Nassuna-Musoke, D.O. Owiny, and Y. Persson. 2014. Characterization of coagulase negative staphylococci from cases of subclinical mastitis in dairy cattle in Kampala, Uganda. Ir. Vet. J. 67:12.

101. Asante, J., U. Govinden, A. Owusu-Ofori, L. Bester, and S. Essack. 2019. Molecular characterization of methicillinresistant Staphylococcus aureus isolates from a hospital in Ghana. Afr. J. Clin. Exper. Microbiol. 20:164-174.
102. dos Santos, F.F., L.C. Mendonça, D.R. de Lima Reis, A. de Sá Guimarães, C.C. Lange, J.B. Ribeiro, M.A. Machado, and M.A.V.P. Brito. 2016. Presence of mecApositive multidrug-resistant Staphylococcus epidermidis in bovine milk samples in Brazil. J. Dairy. Sci. 99:13741382.

103. Pyörälä, S., and S. Taponen. 2009. Coagulase-negative staphylococci-emerging mastitis pathogens. Vet. Microbiol. 134:3-8.

104. García-Álvarez, L., M.T. Holden, H. Lindsay, C.R. Webb, D.F. Brown, M.D. Curran, E. Walpole, K. Brooks, D.J. Pickard, and C. Teale. 2011. Meticillin-resistant Staphylococcus aureus with a novel mecA homologue in human and bovine populations in the UK and Denmark: a descriptive study. Lancet Infect. Dis. 11:595-603.

105. Dhaouadi, S., L. Soufi, F. Campanile, F. Dhaouadi, M. Sociale, L. Lazzaro, A. Cherif, S. Stefani, and R.B. Elandoulsi. 2019. Prevalence of meticillin-resistant and -susceptible coagulase-negative staphylococci with the first detection of the mec $\mathrm{C}$ gene among cows, humans and manure in Tunisia. Int. J. Antimicrob. Agents. 19: $1-5$.

106. Stepanovic, S., P. Ježek, D. Vukovic, I. Dakic, and P. Petráš. 2003. Isolation of members of the Staphylococcus sciuri group from urine and their relationship to urinary tract infections. J. Clin. Microbiol. 41:52625264.

107. Katsande, S., G. Matope, M. Ndengu, and D.M. Pfukenyi. 2013. Prevalence of mastitis in dairy cows from smallholder farms in Zimbabwe. Onderstepoort J. Vet. Res. 80: 523.

108. Ndahetuye, J.B., Y. Persson, A.-K. Nyman, M. Tukei, M.P. Ongol, and R. Båge. 2019. Aetiology and prevalence of subclinical mastitis in dairy herds in peri-urban areas of Kigali in Rwanda. Trop. Anim. Health Prod. 51:20342044.

109. Bekele, T., M. Lakew, G. Terefe, T. Koran, A. Olani, L. Yimesgen, M. Tamiru, and T. Demissie. 2019. Study on bovine mastitis with isolation of bacterial and fungal causal agents and assessing antimicrobial resistance patterns of isolated Staphylococcus species in and around Sebeta town, Ethiopia. Afr. J. Microbiol. Res. 13:23-32.

110. Piessens, V., E. Van Coillie, B. Verbist, K. Supré, G. Braem, A. Van Nuffel, L. De Vuyst, M. Heyndrickx, and S. De Vliegher. 2011. Distribution of coagulase-negative Staphylococcus species from milk and environment of dairy cows differs between herds. J. Dairy Sci. 94:29332944.

111. Tenhagen, B.-A., G. Köster, J. Wallmann, and W. Heuwieser. 2006. Prevalence of mastitis pathogens and their resistance against antimicrobial agents in dairy cows in Brandenburg, Germany. J. Dairy Sci. 89:25422551.

112. Persson, Y., A.-K.J. Nyman, and U. Grönlund-Andersson. 2011. Etiology and antimicrobial susceptibility of udder pathogens from cases of subclinical mastitis in dairy cows in Sweden. Acta. Vet. Scand. 53:36.

113. Schukken, Y.H., R.N. González, L.L. Tikofsky, H.F. Schulte, C.G. Santisteban, F.L. Welcome, G.J. Bennett, M.J. Zurakowski, and R.N. Zadoks. 2009. CNS mastitis: nothing to worry about? Vet. Microbiol. 134:9-14.

114. Lang, S., M. Livesley, P. Lambert, J. Elliott, and T. Elliott. 1999. The genomic diversity of coagulase-negative 
staphylococci associated with nosocomial infections. J. Hosp. Infect. 43:187-193.

115. Lina, B., F. Vandenesch, J. Etienne, B. Kreiswirth, and J. Fleurette. 1992. Comparison of coagulase-negative staphylococci by pulsed-field gel electrophoresis. FEMS Microbiol. Lett. 92:133-138.

116. Harris, S.R., I.N. Clarke, H.M. Seth-Smith, A.W. Solomon, L.T. Cutcliffe, P. Marsh, R.J. Skilton, M.J. Holland, D. Mabey, and R.W. Peeling. 2012. Whole-genome analysis of diverse Chlamydia trachomatis strains identifies phylogenetic relationships masked by current clinical typing. Nat. Genet. 44:413-419.

117. Bakir, M., R. Sabrina, and M. Toufik. 2011. Antibacterial susceptibility profiles of sub-clinical mastitis pathogens isolated from cows in Batna and Setif Governorates (East of Algeria). Vet. World. 4:537-541.
118. Blignaut, D., P. Thompson, and I.-M. Petzer. 2018. Prevalence of mastitis pathogens in South African pasturebased and total mixed ration-based dairies during 2008 and 2013. Onderstepoort J. Vet. Res. 85:1-7.

Address correspondence to: Jonathan Asante, BPharm, MPharm Antimicrobial Research Unit College of Health Sciences University of KwaZulu Natal Private Bag X54001 Durban 4000 South Africa

E-mail: josante33@yahoo.com 